\title{
4Mstate
}

NEUTRON PERSONNEL DOSIMETRY

RICHARD V. GRIFFITH

This Paper was Prepared for Subnitital to

HEALTH PHYSICS SOCIETY SUMMER SCHOOL

Louisville, KY, June 16, 1981

June 36,1981

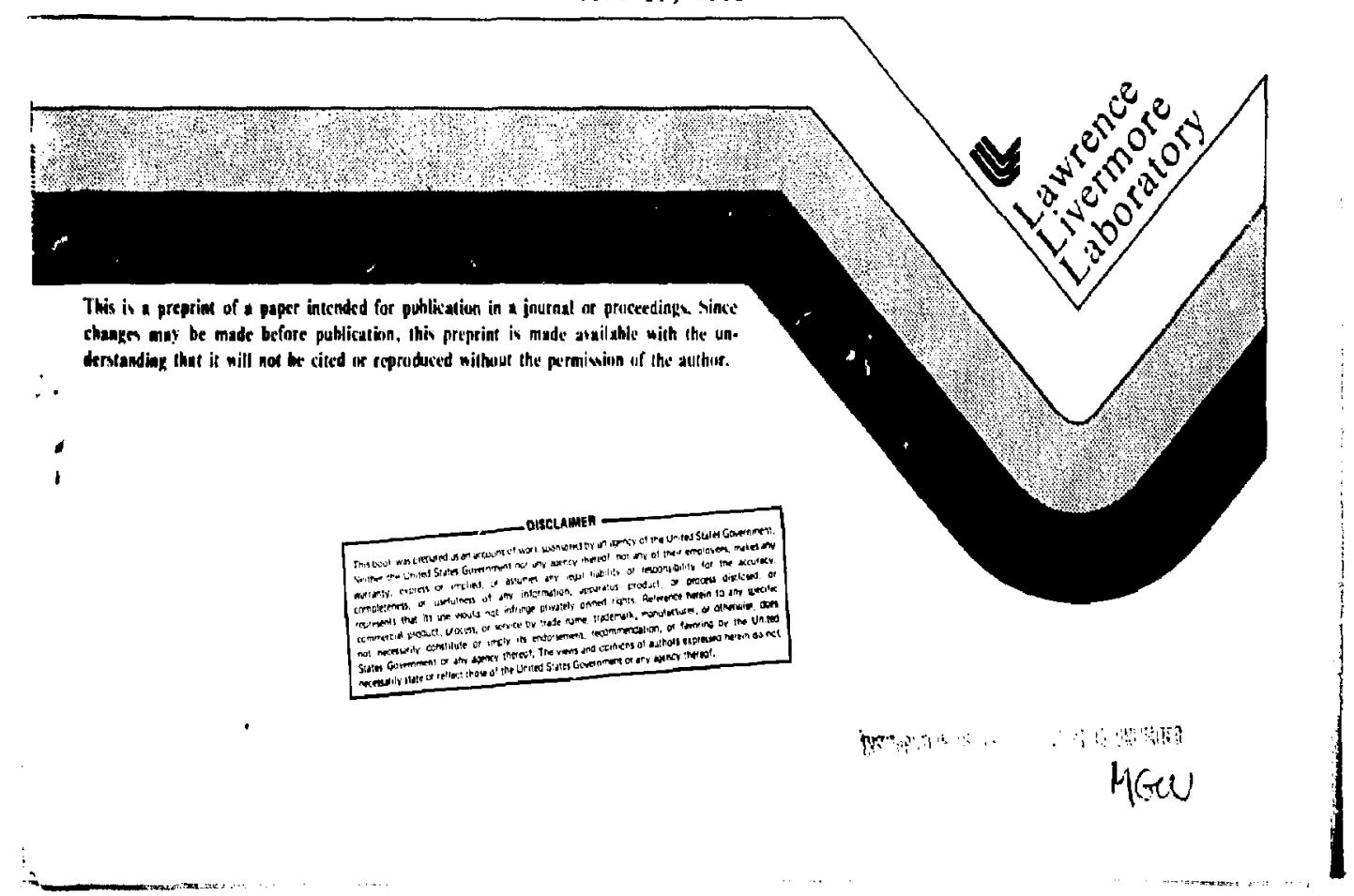




\section{NEUTRON PERSONNEL DOSIMETRY}

Richard V. Griffith

\section{INTRODUCTION}

A recent recomendation to increase quality factors (Ros77, Ros78) has focused reneived attention on the issue of personnel neutron dosi atry. This has only served to heighten the layman's interest in an are that has concerned health physicists for many years - neutron exposure anc personnel neutron dosimetry. The fact is that, even without a change in maximum permissible neutron exposures (through new quality factors or other regulutory change), it is very difficult to provide effective and accurate personnel neutron dosimetry.

In order to understand the special nature of neutron dosimetry relative to that for photons (gamas and $x$-rays), it is important to reviely the comparative interaction processes and the nature of the charged piticles associated with the two types of radiation.

Gamma rays interact with the orbital electrons through

- Photo-electric effect.

- Compton scattering.

- Pair production (above $1.022 \mathrm{MeV}$ ) producing energetic electrons.

Neutrons interact with atomic nuclei through a variety of $(n, X)$ reactions where $X$ can be

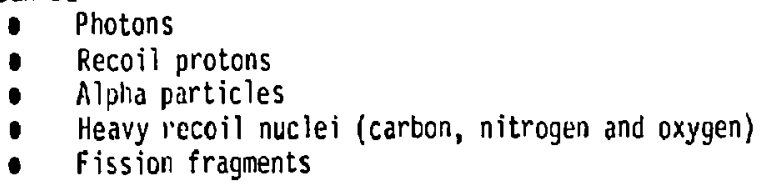

Although some energetic electrons are produced by subsequent secondary photon interactions, neutrons should be thought of as generating heavy charged particles with relatively shorter ranges in matter. In particular, neutron reactions with tissue constituents .. hydrogen, carbon, nitrogen and oxygen -. are of primary interest in biological applications (Health Physics:). Of these, however, hydrogen and associated proton recoils are of greatest interest over the range of neutron energies encountered in most nuclear reactor situations. The kerma (K) fluence to dose conversion (ICRU 69) for these four elements (Fig. I, ICRU69) illustrates the prominent role of hydrogen in neutron dose production quite clearly. Remeniber, of course, that kerma is the anount of initial clarged particle energy $\Delta E_{k}$ per volume element of material, $\Delta \mathrm{m}$. It includes no secondary photon contribution and assumes that $\Delta m$ is so small that it does not appreciably perturb the radiation field. The transition from kerma to dose absorbed in the body will change the dosimetry and contributing factors, but recoil protons remain the most important single factor. 


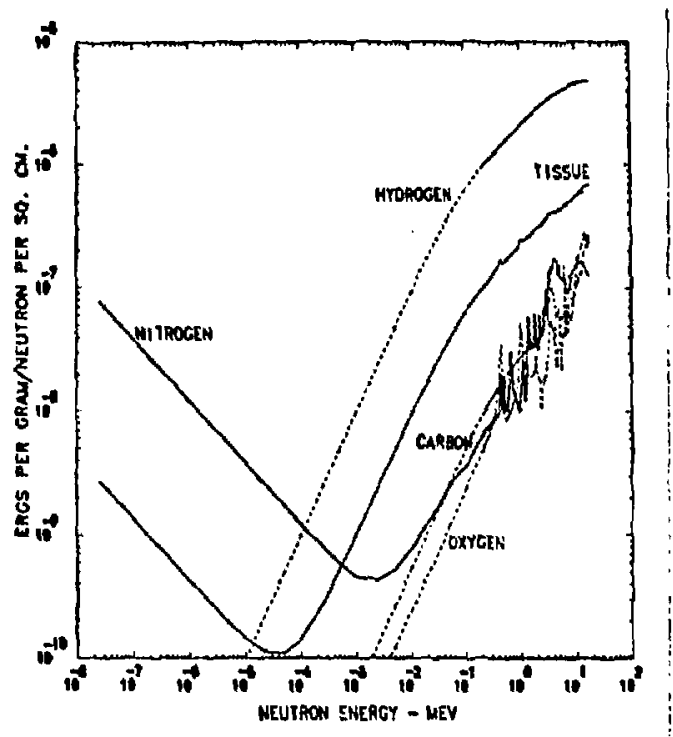

Figure 1. Neutron kerma for hydrogen, carbon, nitrogen, oxygen and soft tissue.

Having established that the photo-neutron comparison effectively implies an electron-proton (or heavy charged particle) comparison for dosimetric purposes, we must consider the concept of linear energy transfer (L.E.T.). Low energy recoil protons have a high ionization density compared with electrons. Alphas and heavy recoil nuclei are still mare densely ionizing. While electrons have L.E.T. values that range up to a few keV per micron, protons achieve values up to $100 \mathrm{keV}$ per micron and heavier particles are perhaps 10 times greater. In terms of cellular damage, a number of studies (IAEA7) have shown that, for equal doses, radiation with greater L.E.T. creates more damage than that for electrons. However, there appears to be an optimuin value of L.E.T. that is most efficient for producing a biological effect. Above that level, the ionization becoiles so dense that energy is wasted as a kind of "overkill". This description is only qualitative. The specific response can vary greatly depending on the biological endpoint, and, in some cases, the response may appear to be independent of L.E.T. However, the L.E.T. dependent response has been observed in many biological systems and is illustrated conceptually in Figure 2. 


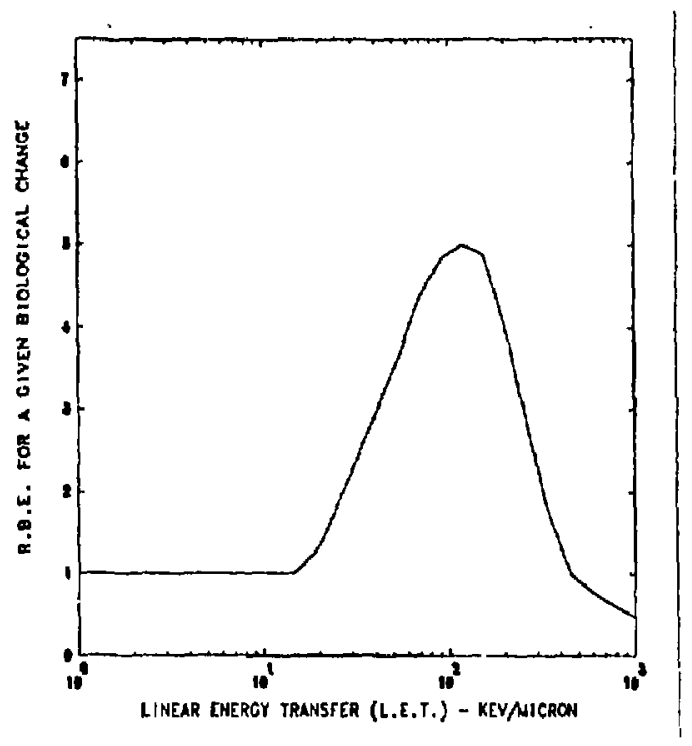

Figure 2. Illustration of L.E.T. Dependent Relative Biological Effectiveness (R.B.E.).

In order to adjust for differences in the radiotoxicity of different radiation qualities, the concept of Dose Equivalent (DE) was develared. In its simp?est form,

$$
D E=D \cdot Q_{F}
$$

Where 0 is absorbed dose

$Q_{F}$ is the Quality Factor

Quality factor (NCRP54, ICRP/ICRU63) is an L.E.T. dependent correction factor (Fig. 3, NCRP 71). Note the similarity in Figures 2 and 3 , with the exception that $Q_{F}$ takes no credit for overkill at high L.E.T. values, and is therefore constant (and probably conservative) above $200 \mathrm{keV} / \mathrm{\mu m}$. 


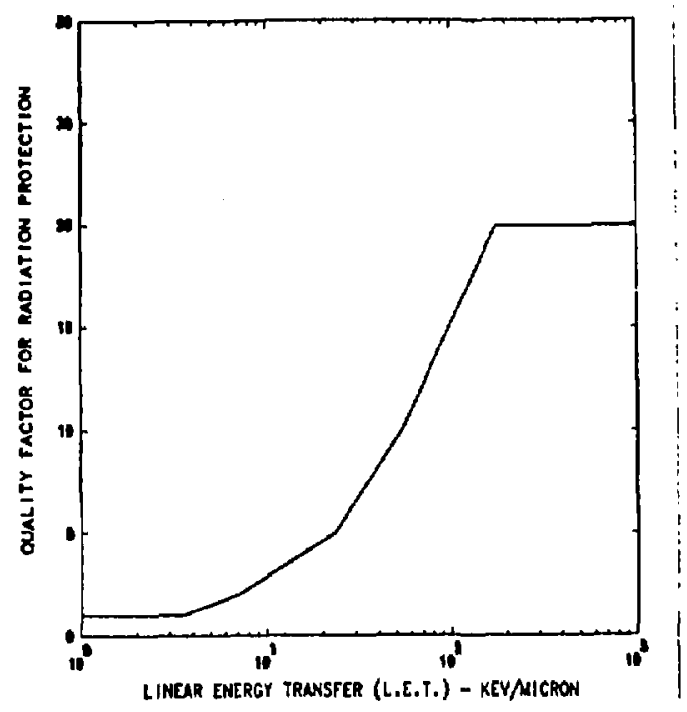

Figure 3. L.E.T. Dependent Charged Particle Quality Factor.

Armed with the definition of dose equivalent, a number of scphisticated conputer calculations have been performed that define the proper fluence-to-dose equivalent conversion factors over a wide range of energies (Aux68, NCRP71). The results appear in tabular form (Table 1), or interpolated and inverted (Fig. 4). As an aside, there is currently a controversy over the proper interpolation technique (Rog78, Eis81, Klu81). The implied interpolation uncertainties are illustrated in figure 4 . Over most of the energy range, the interpolation choice makes little difference. The differences are most pronounced in the range between $10 \mathrm{keV}$ and $500 \mathrm{keV}$, where recent measurements (Han78, End80, San80) have found a large neutron contribution in power reactor environs.

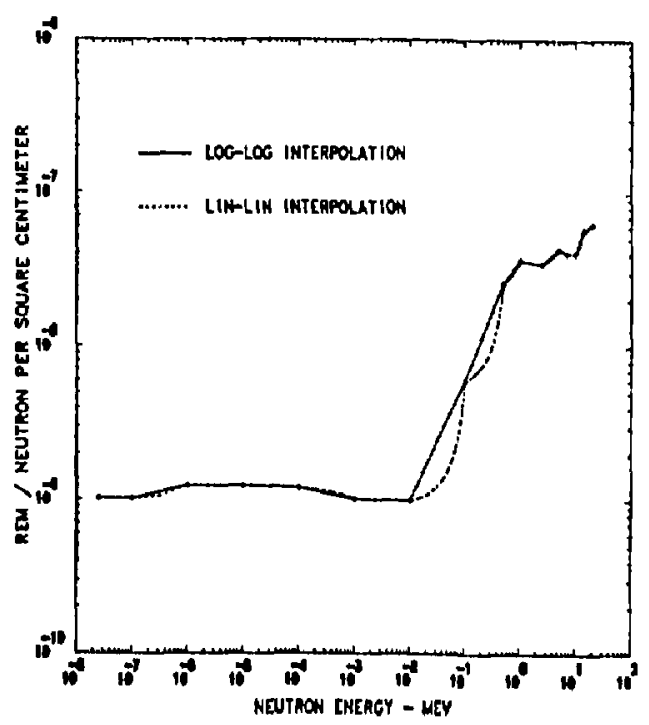

Figure 4. Neutron Fluence-to-Dose Equivalent Conversion Factors. 
Table 1

\section{Neutror-Dose Equivalent Conversion Data}

\section{Neutron Energy Neutron Fluence for a Fluence-to-dose Equivalent \\ $\mathrm{MeV}$ \\ 100 irem dose equivalent in \\ rem $\cdot$ Neutron ${ }^{-1} \cdot \mathrm{cmin}^{2} \times 10^{3}$ \\ a 40 hour working period.}

$\begin{array}{lll}2.5 \times 10^{-8} \text { (Thermal) } & 680 \mathrm{~cm}^{-2} \mathrm{sec}^{-1} & 1.02 \\ 1 \times 10^{-7} & 680 & 1.02 \\ 1 \times 10^{-6} & 560 & 1.24 \\ 1 \times 10^{-5} & 560 & 1.24 \\ 1 \times 10^{-4} & 580 & 1.20 \\ 1 \times 10^{-3} & 680 & 1.02 \\ 1 \times 10^{-2} & 700 & 0.992 \\ 1 \times 10^{-1} & 115 & 6.04 \\ 5 \times 10^{-1} & 27 & 25.7 \\ 1 & 19 & 36.5 \\ 2.5 & 20 & 34.7 \\ 5 & 16 & 43.4 \\ 7 & 17 & 40.8 \\ 10 & 17 & 40.8 \\ 14 & 12 & 57.9 \\ 20 & 11 & 63.1\end{array}$

Another issue that should be discussed is the concept of Dose Equivalent Index $\left(H_{I}\right)$. $H_{i}$ has been developed in response to limitations associated with the present definition of dose equivalent (ICRU76). Based on a $30 \mathrm{~cm}$ tissue sphere, $H_{I}$ is intended to overcome problems the existing definition. However, the new definition brings with it a new set of problenls, including non-additivity in space, and neutron energy (Hag80). To date, there have been no published fluence-to- $H_{J}$ conversion factors. There is a feeling among many, if not most, dosimetrists that $H_{\text {I }}$ has created more problems than it solves.

\section{Dosimetry Needs and Alternatives}

Before selecting a dosimetry system, we need to review the rules. For NRC licensees, Regulatory Guide 8.14, Personnel Neutron Dosineters outlines requirements for dosimeter issue, performance, fading, and system calibration. It also lists permissible alternative methods of dose equivalent evaluation -- personnel dosimeters, neutron to garma ratios and dose 
calculated from survey instruments and stay time. Much of its guidance is based on an American National Standards Institute publication (ANSi76). Basically, however, it requires,

- Dosinetry if the quarterly dose received by a worker is likely to exceed 300 miem.

- An average accuracy of a set of 10 dasimeters of $\pm 50 \%$ when exposed to unmoderated ${ }^{252} \mathrm{Cf}$ spontaneous fission neutrons.

- A fading error of less than $40 \%$.

- Dosimeter precision -- Standard Deviation of $\pm 30 \%$ for the response of a sat of at least 10 dosimeters exposed under identical conditions to a neutron source at a dose equivalent level of approximately $\mathrm{rem}$.

It should be noted that Regulatory Guide 8.14 is currently under revision. The new version is expected to give more restrictive guidance on acceptable dosimeter types to be used for specific applications, particularly at power reactors.

Another effort to improve personnel dosimetry in general has been the establishment of a testing laboratory, funded by the NRC. Although the main thrust is the testing of dosimeters for photons and betas, neutron dosimeters are included in the testing schedule. Presently orily fast neutrons (unmoderated ${ }^{252} \mathrm{Cf}$ ) are used, a standard moderated ${ }^{252} \mathrm{Cf}$ field is being considered (SchBO) as a more rigorous test of dosimeters to be used at power reacturs. The protocol of the test lab is based on an ANSI standard that should be published this year (ANSI81), and has been used in a trial and evaluation mode for the last few years. In order for a dosimetry service to be certified, they will have to pass the prescribed tests for each of eight classes of dosimetry for which their dosimeters are designed to be used ( $x$-rays, gammas, betas, neutrons and certain mixtures thereof).

\section{CURRENT DOSIFETRY APPROACHES}

Three techniques for estimation of the neutron dose equivalent are currently in common use.

- Personnel Dosimeters - Small, usually passive, neutran sensitive devices yorn at strategic locations on the body. The locations depend on the anticipated special distribution of the neutron field. Normally, the fields are assumed to be uniform, with the dosimeters worn on the trunk of the body, at or above the waist. For applications requiring manual manipulation of a neutron emitting item, a specially designed finger ring dosimeter can be used. 
Typical (though not universal) disadvantages of personnel dosimeters include,

- Lack of real time dose information due to need for laboratory readout and evaluation.

- Limited sensitivity.

- Difficulty in mimicking the dose equivalent conversion factor energy response.

- Large variation in response as a result of body orientation with relation to the field direction.

- Sensitivity to photon radiation for some dosimeter detection mechanisms.

- Loss of signal or fading following exposure. This is norinally only a problem for photographic film dosimeters.

On the other hand, personnel dosimeters are,

- Small and convenient to use.

- Provide ineasurements at the body, where the radiation is of greatest concern.

- Generally inexpensive and can be used in large quantities.

- Survey Instrument Readings and Stay Times - Health physicists often choose to take advantage of the high sensitivity, good energy response characteristics, and relative orientation independence of portable neutron survey instruments when making personnel dose assessments. The method is to make a survey of the working area with the instrument to establish the dose rate. By recording the length of time a worker stays in the area, it is easy to calculate the dose equivalent. If, however, there is a significant spacial variation in dose rate, comensurate errors in the dose equivalent estimate develop. A similar approach is to use an integrating scaler with the instrument, and work with the remmeter near by. Again, however, if a number of people are involved, that are not working close to each other, the original problem persists. Finaliy, although the remmeter has specific measurement advantages over the personnel dosimeter, there are inaccuracies in energy response and directional dependence that should not be ignored (ROg79, Han74, Han75a, Han7\%).

- Neutron to Ganma Ratios - Gama dosimeters are generally considered to be more accurate and dependable for personnel monitoring than neutron dosimeters. They are certainly used in greater numbers. If the relative dose contributions from the neutrons and gaminas maintain a constant ratio throughout the occupied. areas of a radiation producing facility, it is possible to infer the neutron contribution to a worker's dose from the results on the gamma dosimeter. In fact, this technique can be used, but with caution. 
- Sufficient surveys must be taken throughout the area with portable instrumentation to determine that the $n / \gamma$ does not vary excessively (probably by no more than a few tens of percent).

- Surveys should be repeated or rechecked periodically to make sure that changes in shielding or the radiation source have not changed these ratios.

- The health physicist should compare the energy response of the gamma survey instrument with that of the personnel dosimeter to make sure that the photon doses measured by the dosimeter are the same as those used to determine the instrumental n-garma ratio.

Since each of these techniques has practical and/or technical advantages, it may be wise to apply all three in some combination to determine the neutron dose. An additional advantage to using more than one dose estimation technique is the ability to spot anomolous results and pick up errors that have crept into some aspect of the dosimetry program.

IV. PERSONAEL MONITORING DEVICES

Selection of personnel neutron dosimeters and survey instruments depend on a number of factors.

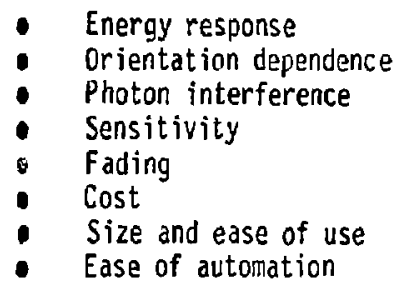

These factors have to be weighted by the characteristics of the radiation field, and the operational limitations of the radiation safety program before . proper selections can be made.

Since the measuring instrument is intenced to determine dose equivalent, it is valuable to mimic the energy dependent fluence-to-dose equivalent conversion as closely as possible. However, few instrunents achieve that goal, to even a reasonable approximation. Therefore, it is important to know something about the spectral characteristics of the neutron field. That is, what energy range represents the bulk of the dose equivalent contribution, and what is the relative response of the instrument or dosimeter in that range? Moreover, are there significant variations in the spectra throughout the working area that would contribute significantly to errors in dose evaluation?

The fields in power reactors have been measured extensively over the last felr years (San80, End80), in large part motivated by the dosinleter energy response issue. Typical spectra are presented in Fig. 5. Although there is significant facility-to-facility variation, these spectra do show large contributions from neutrons in the intermediate range (1 kel - $500 \mathrm{keV}$ ). By contrast, most dosineters and instruments are calibrated with fast neutron sources ( ${ }^{252} \mathrm{Cf},{ }^{231} \mathrm{PuBe}$, etc.). The errors produced using dosineters or instruments having a poor energy response, considering this spectral' mismatch, can be considerable (factors of 10 or more). 


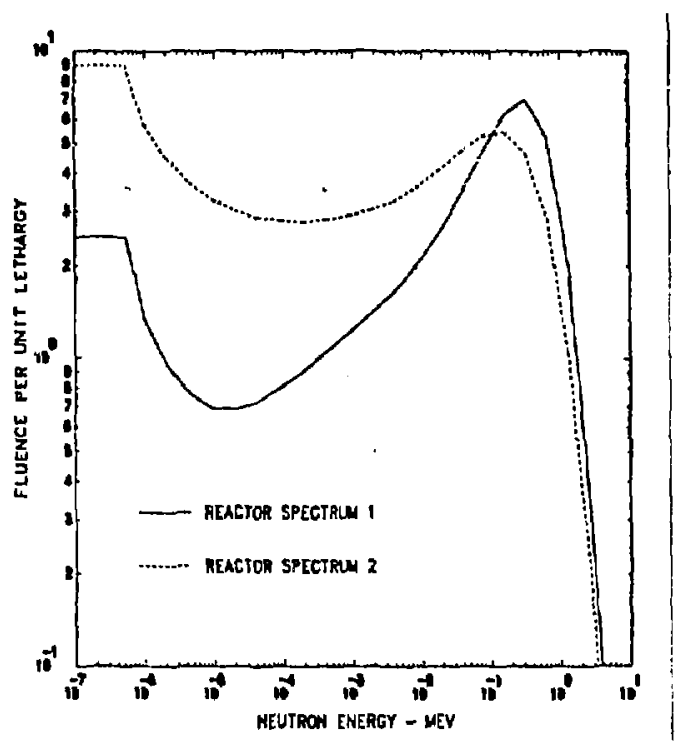

Figure 5. Neutron spectra from two, typical nuciear power reactor locations in containment. (Lethargy units present the spectrum by relative neutron contribution as a function of energy; $i . e .$, a I/E. spectrum is constant in lethargy units.)

\section{A. Personnel Dosimeters}

Detectors used for personnel neutron dosimetry can be considered to fall into two classes:

- Bulk Detectors.

Those dosimeter mechanisms that involve measurement of a radiation induced signal integrated over the detector volume. Thermoluminescence is a prime example of this class of detectors. The entire detector is heated and read out at the same time. There is no capability for analyzing the microstructure of the energy deposition process.

\section{- Track Detectors}

These detectors depend on formation of tracks in the detector volume, which can be processed and made visible or sensible in some fashion. NTA film is the classic track detector, although probably not the bcst neutron dosimeter currently available. Detection by track formation enhances the ability to discriminate against low L.E.T. photon radiation. A major drawback usually associated with track detectors is a tedious readout process. However, as we shall see, techniques are now available to relieve that concern. 
What follows in this section is a discussion of detection mechanisms embodied in dosimeters that are currently in use for routine personnel monitoring. A brief review of new techniques under study will appear in a subsequent section. Such methods are interesting, but of little practical value to someone in need of immediate solutions. Criticality monitoring is not included. However, good references are available on that subject (IAEA73, IAEA78, Maj80, ANSI69).

\section{Albedo Dosimeters}

This currently is the lone bulk detector entry in the personnel neutron dosimetry array. Simply stated, an albedo dosimeter is a thermal detector that depends on reflected (albedo) neutrons from the body of the wearer to enhance its fast neutron response. There are a wide variety of albedo designs involving cadnium (Fal7l, Hoy72, Han73) or boron (Har72, Pie74) to shield the thermal detector from incident neutrons. However, the basic principle is the same.

The detector usually employed is a Lif thermoluminescent detector (TLD), usually enriched in ${ }^{6} \mathrm{Li}$. The " $\mathrm{Li}(\mathrm{n}, \mathrm{alpha}$ reaction provides the neutron response. It is presented in Fig. 6 , and the calculated albedo neutron dosimeter response $(A \mid s 74$ ) is shown for comparison. In contrast with Fig. 4, it is clear that the albedo energy response is not even close to simulating the dose equivalent response. However, albedo dosimeters have the distinct advantage of employing dosimetry techniques that have been highly automated for photon dosimetry applications. Moreover, if the working area does not have severe spectral variations, a well calibrated albedo system may well be superior to other alternatives.

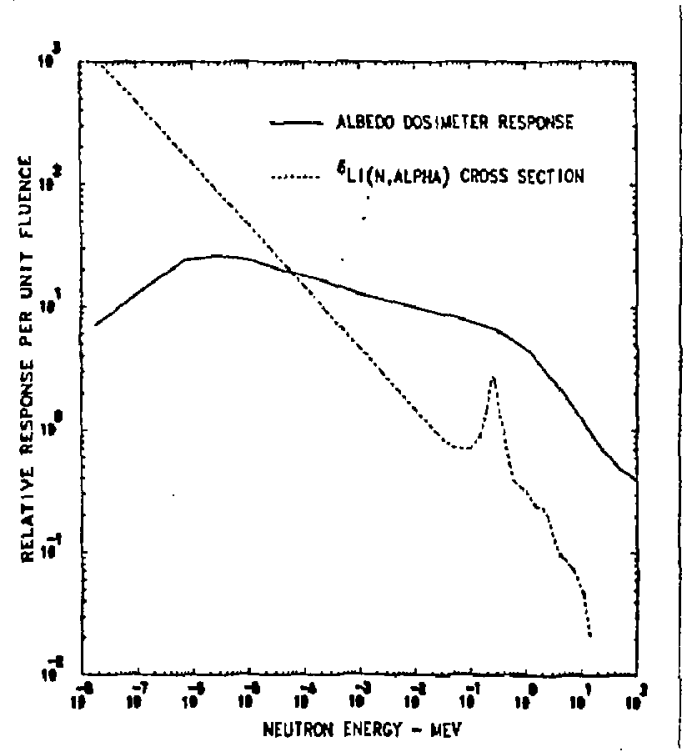

Figure 6 . Neutron energy response of a ${ }^{6} L$ if TLO albedo dosimeter compared with the ${ }^{6} \mathrm{~L} i(N$, alpha) cross section. 
One additiona? advantage of the albedo dosimeter is that the arientation dependence (Fig. 7, Pie77) is not as severe as some of the recoil track detectors. Care must be taken to make sure that the dosimetei is worn close to the body. The detector-body combination is, in effect, the dosimeter, so variations in that relationship will result in errors in response, sometimits as much as $50 \%$ or more (Han72a, Han72b).

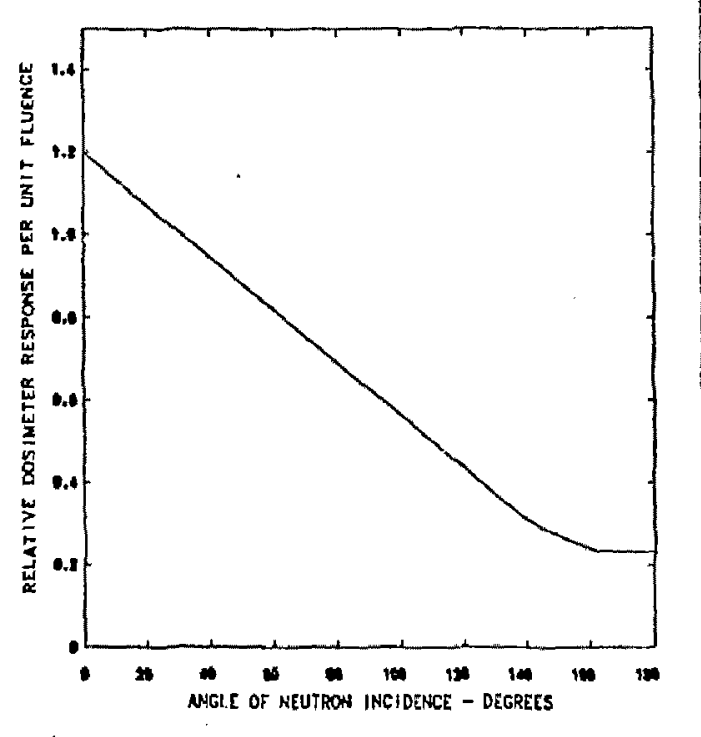

Figure 7. Orientation dependence of TLO albedo dosimeter (measured on a phantom).

i :e photon response of the ${ }^{6} \mathrm{~L} i \mathrm{~F}$ is determined by including a neut" an inselsitive companion ${ }^{7} \mathrm{~L}$ iF $T L D$, and subtracting that response from the ${ }^{6} \mathrm{Lif}$ (assuming proper correction for jifferences in photon response due to size, etc.). However, in fast neutron fields (unmoderated fission, etc.), the photon response can limit the lower limit of neutron detection. Hore moderated spectra (at power reactors for example) result in a greater albedo response per unit dose equivalent (Fig. 6). Photon sensitivity in such applications is not generally a serious prob?em. Finally, Tlo fading is also not a particular concern, amounting to only a few percent per month under the most severe conditions that would be endurer by a radiation worker.

\section{NTA Film}

Fi?m dosimeters are the most familiar to those who have worked with radiation for a long time. As mentioned earlier, they are classic track detectors. In principle, the neutron interacts with a hydrogen nucleus in the sensitive layer of the film. The energetic proton that results travels a short distance (few microns), depositing energy in the silver halide imbedded in the emulsion. When the film is developed, the track path is visualized as a short, linear trail of free silver grains. The number of tracks per unit film area can be counted with an optical microscope and related to neutron fluence or dose equivalent. Rancom grains produced as the result of low 
L.E.T. electron interactions are not generally confused with the heavier charged particle since at least three grains are generally considered necessary to constitute a track. A three grain track is equivalent to the range of a proton produced by interaction with a neutron of approximately $0.5 \mathrm{MeV}$. This energy then represents the practical threshold of the film. The $N(n, p)$ reaction with nitrogen in the emulsion produces 0.6 MeV protons from thermal neutrons, so there is some sensitivity to low energy neutrons. However, the thermal response of NTA film is not significant for most applications.

The fact that the NTA detection mechanism involves proton recoil measurement made it an attractive dosimeter for many years, particularly because there were no practical alternatives. Indeed it does have an adequate fast neutron response for some applications (Fig. 8, Say?h). A comparison of Figs, 5 and 8 suggest a significant problem in the application of NTA at reactors because of the large number of low energy reactor neutrons that occur below the filin threshold. Moreover, photographic film is sensitive to environmental factors (heat and humidity) that work to reverse the track forming process. As a result, film has developed a terrible reputation for fading, unless a great deal of care is made to package the film tightly. This, of course, helps the humidity problem, but not the heat (Fig. 9, Say74). The fading issue is of particular concern for environments rich in neutrons below 1 Mev since fading will be more important for the 3 and 4 grain träcks than those that are longer.

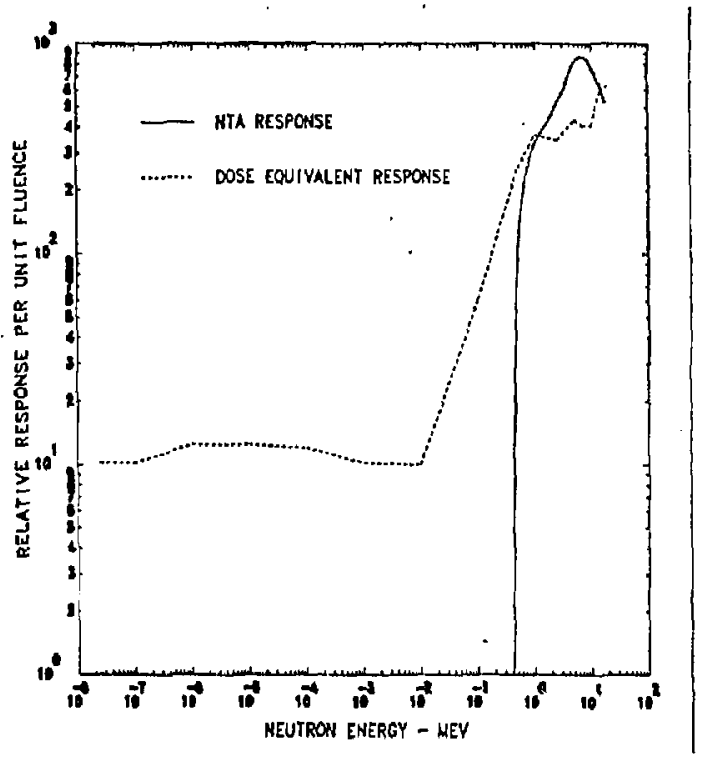

Figure 8. Neutron response of NTA film. 


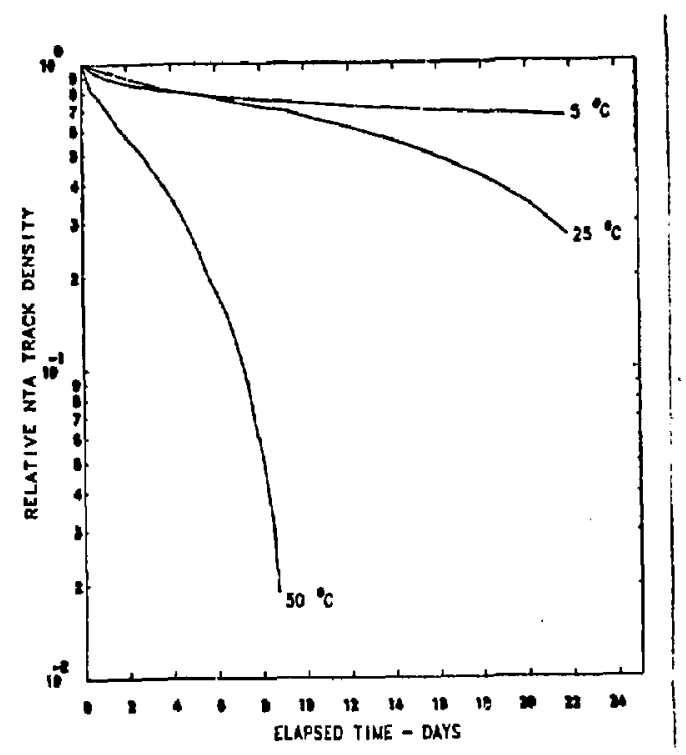

Figure 9. Fading of NTA film, sealed and stored at $50 \%$ relative humidity. (Track density - tracks per $\mathrm{cm}^{2}$ )

As a fast neutron detector, NTA is influenced significantly by orientation and shielding by the body which would moderate neutrons incident from the rear (Fig. 10, 0sh73). Like other track detectors, the effect is much more severe than for the low energy sensitive detectors.

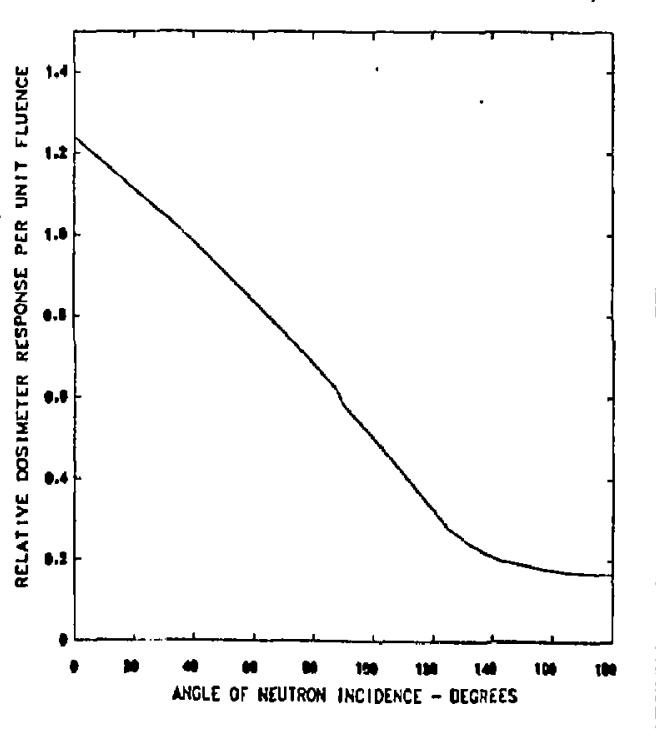

Figure 10. Orientation dependence of NTA film (measured on a phantom). 


\section{Fission Track Detectors}

The dosimetric advantages in using $n$, fission reactions with heavy nuclides (232 Th, ${ }^{235} \mathrm{U},{ }^{238} \mathrm{U},{ }^{233} \mathrm{NP}$ and ${ }^{239} \mathrm{Pu}$ ) were demonstrated many years ago (Hur58, Rei58). A second real advance came when etch track detection techniques (Pri62) were applied to detection of the individual fission fragments. Etch track detection involves enlargement of latent damage tracks in dielectric materials to dimensions that are visible with an optical microscope. The gram quantities necessary for radioassay of the induced fission products could be reduced a thousand times to the amount of material needed to act as a fission fragment radiator. The fission track technique was eagerly adopted world-wide for criticality monitoring (IAEA7D, IAEA78, ANSI69, Maj80).

Some laboratories have used fission track detectors for personnel monitoring for personnel dosimetry (Har78, Yul73, Dis73, Pre73). However, general use has not been enthusiastic. The two biggest obstacles are: (1) The perceived radiation hazard associated with personal use of even militigram quantities of materials such as ${ }^{233} \mathrm{~Np}$ and $232 \mathrm{Th}$, and (2) The cost involved in preparing large numbers of radiators. This is particularly true of $237 \mathrm{~Np}$, which most closely simulates the dose equivalent response over the full energy range (Fig. Ii). Neptunium either must be vapor plated (Har78) or introduced in ail inert matrix (Cro75). In either case, the production cost is not trivial for a large dosimetry program. Thorium can be used as thin foils, and is less costly; however, the response has an energy threshold that is too high for most applications (Fig. 12).

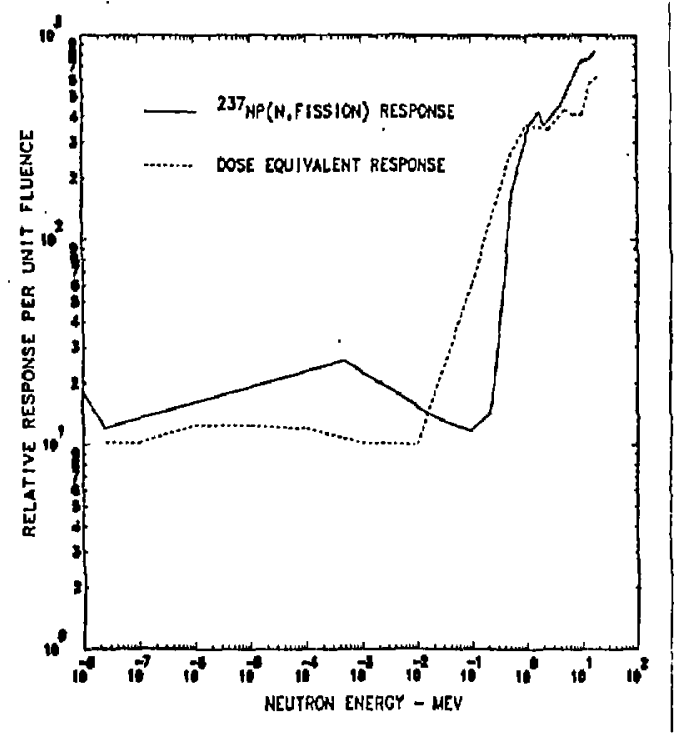

Figure 11. Relative neutron response of a ${ }^{237} \mathrm{~Np}$ fission track dosimeter. 


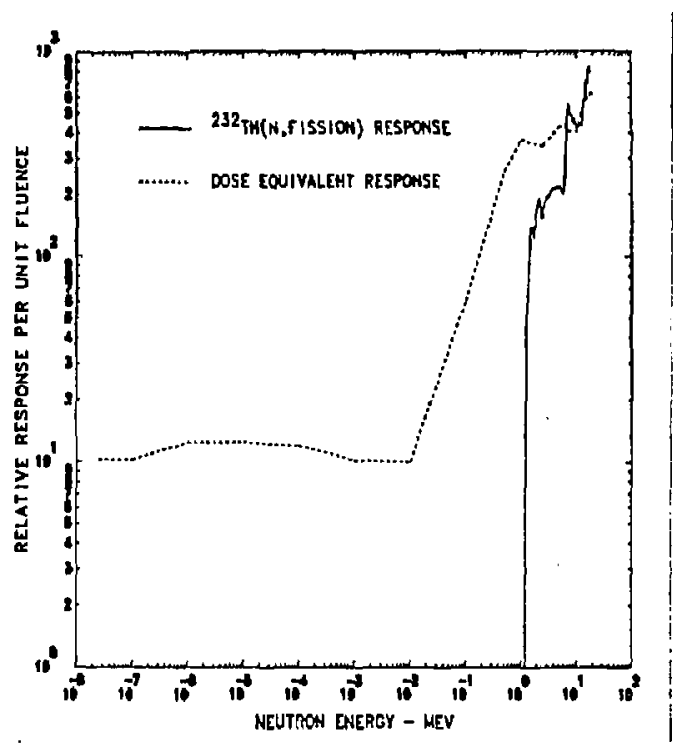

Figure 12. Relative neutron response of $a^{232}$ Th fission track dosineter.

Like NTA filin, the counting of etch tracks with a high magnification optical microscope can be a tedious process, and not easily automated. Spark counting (Cro70) was the first of a series of three electrical breakdown techniques to be applied to easing the track counting process. Very simply, a thin film $(210 \mathrm{~km})$ of track detector, usually polycarbonate, is etched in a conventional caustic process. Then, however, it is placed between two electrodes to form a simple capacitor. When a voltage of a few hundred volts is applied to the capacitor, individual damage tracks break down resulting in a voltage drop that can be detected with a pulse counter. One of the electrodes is a metallized plastic (usually aluminized mylar). When a spark occurs through the track, an area of metal larger than the breakdown hole is burned away, preventing a given track from being counted twice. Moreover, the circuit can be designed to allow the pulse to drop below a certain level before a second track breaks down. This prevents coincidence losses. This technique has been used very successfully in at least two dosimetry programs (Har78, Pre73). However, it is semiautomatic, requiring some manual samiple changing. Also, the upper level of detection is limited by track overlap to a few thousand tracks/col? . The dose equivalent represented by this level depends on the type of radiator used, but would be equivalent to a few 10 's of rem.

Fading of fission tracks has not been found to be a serious problen for the length of time involved in routine dosinetry changes (Say74). However, like NTA, the orientation dependence can be severe (Fig. 13, Soh72). The use of radioactive material is probably the key issue preventing widespread use of fission dosineter techniques. ${ }^{232}$ Th has been used in some routine dosimetry programs. The Chalk River Laboratory in Canada uses ${ }^{237}$ Np routinely. The mast sensitive fission dosimeter is used by the British, and employs a relatively thick radiator of neptunium in a lead lined case. It is, in fact, 


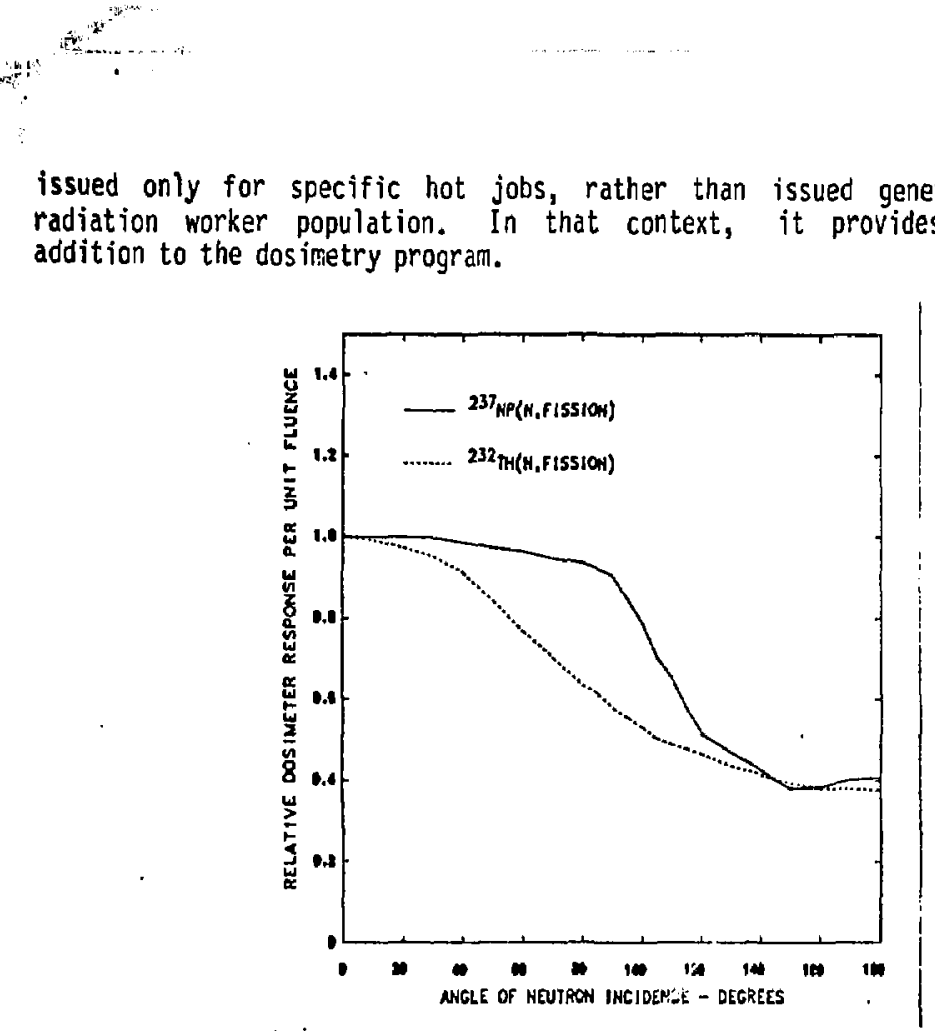

Figure 13. Orientation dependence of ${ }^{237} \mathrm{~Np}$ and ${ }^{232}$ Th fission track dosimeters (measured on a phantom).

\section{Recoil Track Detectors}

The advantages of etch track detection have caused increasing interest in finding techniques that do not have the disadvantages associated with fission foils. Over the last 10 years, a number of investigators have developed systems based on detection of recoiling nuclei of the plastic detector consitutents $(H, C, N$ and 0$)$, or alpha particles from $n$, dipha reactions in non-toxic radiators containing ${ }^{10} \mathrm{~B}$ or ${ }^{6} \mathrm{~L} i$. It is the same ${ }^{6} \mathrm{~L} i(\mathrm{n}$, alpha) reaction used in albedo techniques, but detected with etch track rather than TLD methods.

A track detector can register charged particles only if the particle in question has an L.E.T. that exceeds the detection threshold of the material (Fle67, Fle75). The threshold depends to some degree on specific formulation and treatinent. However, the generic material is most important. Studies over the years have shown the celluiosic materials to be the most sensitive, with cellulose nitrate generally having the best track formation properties. Protons are detectable with conventional etching techniques. Polycarbonates are not as sensitive, but are capable of detecting heavy recoils, and alpha particles (with proper processing). Proton detection has yet to be demonstrated clearly, although there have been some reports to that effect. Host recently, a carbonate -. CR-39 -. has been studied extensively, and appears to be at least as sensitive as cellulose nitrate (Cas78, Car79, Ain79, Gri81). Other materials generally lack sensitivity and are not now applied routinely for dosimetry on a large scàle. 
A major consideration must be given to easing the processing problem when large numbers of track detectors are involved. The counting process is a key part of this problem, and a lot of effort has been devoted to making count ing easier. Attempts have been made to apply spark counting to detection of direct recoils (Bec75, Jas75), but, problems of reproducibility and quality control have not been solved. A rommercial cellulose nitrate -- LRI15, nlade by kodak Pathe -. has been formulated with a deep, red dye included in the $14 \mathrm{~m}$ thick sensitive layer. As the recoil tracks etch through, they become pin holes in the dark background and can be counted with relative ease with an optical microscope. The response seems to be highly dependent on the range of the charged particle (i.e., neutron energy). Therefore, LRII5 can probably be uscd effectively only for relatively high energy neutron measurement (Fig. 14, Gri81). Designs have been developed using ${ }^{6} \mathrm{Li}$ or ${ }^{10}{ }_{B}{ }^{\circ}$ loaded radiators (Tym73, Dut79), but they seem to lack sensitivity in a major range of interest for most reactor applications -. 0.1 to a few MeV.

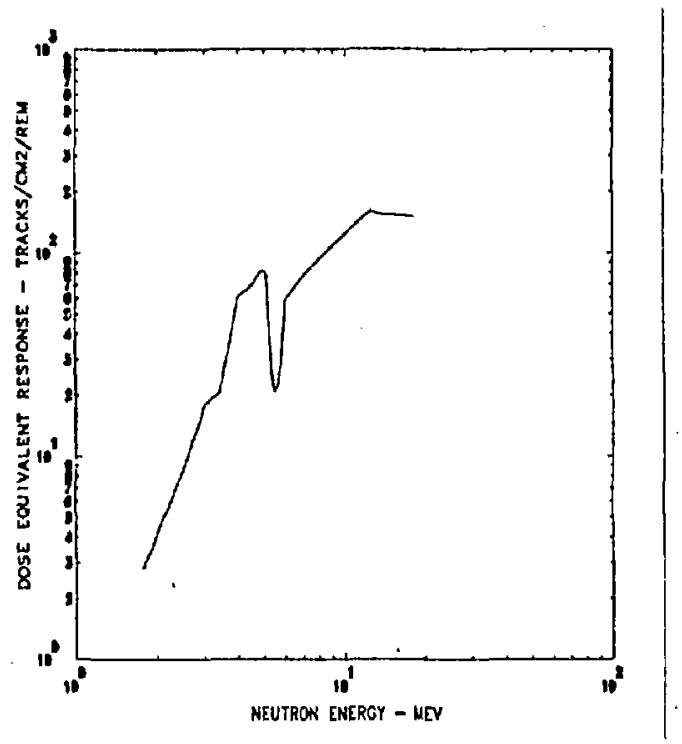

Figure 14. Neutron dose equivalent response of $L R T 15$ track etch detectors.

The second of the three breakdown processes -- electrochemical etching -can be used to improve track visibility significantly (Tom70). In concept, the dielectric (usually plastic) sample separates two volumes of caustic electrolyte. An A.C. voltage is applied across the sample, through the electrolyte. The conventional etching process enlarges latent tracks until they become fine, conducting needles. The A.C. field then causes a non-shorting breakdown at the needle tip and a relatively large $(50-200 \mu \mathrm{m})$ subsurface "tree" or void is formed. The trees are large enough to be counted easily with a microfiche reader. The process was demonstrated originally with fission fragments and alpha particles, but was extended to detect recoils in polycarborate (Soh74). The neutron energy response of electrochemically etched polycarbonate is superior to that of LRII5, but still lacks necessary sensitivity below $1 \mathrm{MeV}$ (Fig. 15, GriB1). A dosimetry service using 
electrochemically etched polycarbonate is available conncrcialily. At least one other company is, or will be marketing a product based on a design that uses ${ }^{10} \mathrm{~B}$ loaded radiators to extend the response to thermal energies (Eis80).

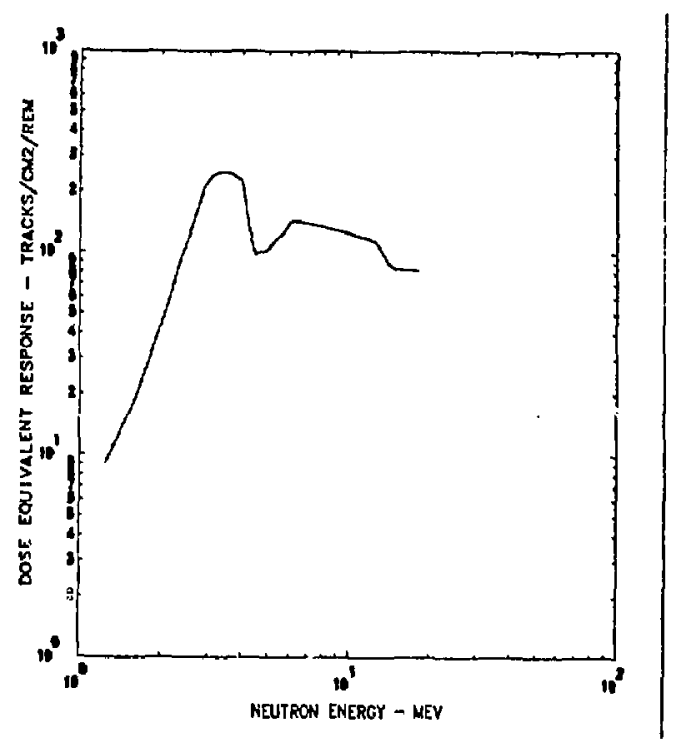

Figure 15. Neutron dose equivalent response of electrochemically etched polycarbonate.

CR-39 was introduced as a sensitive charged particle detector, and measurements of the enerqy response using both conventional and electrochemical etching seen to bear this out (fig. 16, Gri8l). The conventional etching provides higher sensitivity and a commercial CR-39 dosimeter using this process is now available. However, the tedium and identification problems of counting the tiny tracks will force many people to electrochemicaliy etching. An interesting side light is the advantage of using a chemical pre-etch with the CR-39. Proton tracks take longer than high L.E.T. heavy recoils to etch and are not detected by electrochemical etching alone because of time limitations. If one pre-etches the sample for 1 to 5 hours at elevated temperatures $\left(260^{\circ} \mathrm{C}\right)$, these tracks do develop and can be electrochemically etched. The result is a factor of 10 to 100 improvement in sensitivity. Like the polycarbonate, CR-39 electrochemical etching requires electric fields of $30 \mathrm{kV}$ per $\mathrm{cm}(2000 \mathrm{~V}$ for a $0.025 "$ thick sample) and frequencies of 2 to $10 \mathrm{kHz}$. Cellulose nitrate, incidentally, does not yield electrochemical etch tracks that even approach the quality of those obtained from polycarbonate or CR-39, and has not been used for that reason. 


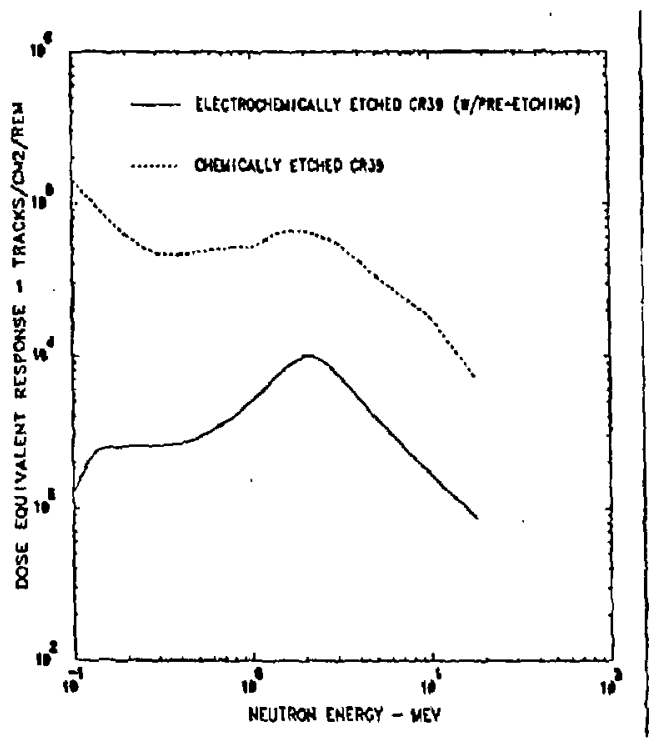

Figure 16. Neutron dose equivalent response of conventionally and electrochemically (with pre-etch) etched CR39.

The dosimeters just discussed have been considered for use by themselves, that is as if only one detection mechanism were to be employed. However, there is growing emphasis on using two or more mechanisms in combination, packaged in one badge $\langle 0 i 573$, Gri30a, Eis80). Tyoically, this means an albedo detector plus a threshold detector or detector(s). The albedo detector can use traditional TLO techniques, however, track etch analogues can also be used to reduce gamma sensitivity (Dut79, Eis80). By using the highly sensitive albedo component to screen out low exposures, one can avoid processing all but a few threshold detectors. In principle, the mult iple component approach can improve the quality of the dosimetry, without serious increase in effort.

\section{B. Survey Meters}

\section{Remmeters}

The advantages of using survey instrumenis to augment personnel dosimeters has been discussed, and need no amplification. Commercially available survey instruments are based on moderated detector techniques. A small detector that has a high thermal cross section $\left({ }^{10} \mathrm{BF}_{3},{ }^{3} \mathrm{He}\right.$, ${ }^{6} \mathrm{LiI}$, etc.) is placed in the center of a spherical or cylindrical hydrogenous moderator (usualiy polyethylene). The moderator absorbs most thermal and intermediate energy neutrons, while fast neutrons are moderated for easy capture by the detector. The overall response of the detector is thus modified to emphasize fast neutron detection. If the proper thickness of muderator is used, the response simulates the dose equivalent response to within a few percent over a large portion of the neutron energy range. More carefut attention to design details (use of special thermal neutron absorbing levels, etc.) have been used to tailor the response to match the dose equivalent coversion curve even more closeiy (And63, Han6?). 
Two comercially available instruments are in routine use currently in the United States $-\cdots$ a 9 inch diarneter spherical detector (Han67) made by Eberline Corporation and the Andersson-Braun cylindrical remmeter (And63). The version known as Snoopy is no longer made in the United States. However, Studsvik in Sweden produces their own model. Both remmeters use $\mathrm{BF}_{3}$ detectors. The 9 inch remeter has better directional dependence properties (Fig. 17, Han74), however the Andersson-Braun remmeter is more sensitive and matches the dose equivalent response more closely (Figs. 18,$19 ; \operatorname{Han} 77$ ).
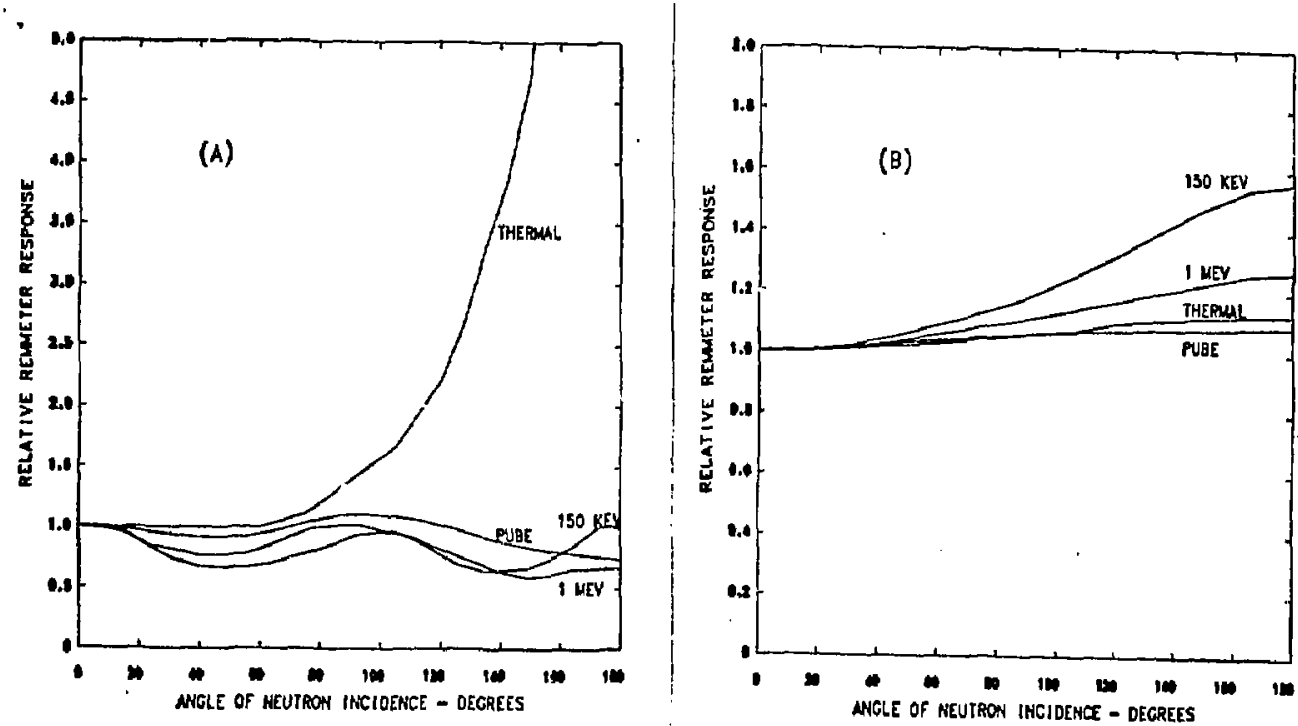

Figure 17. Directional response of the: $(A)$ Andersson-Braun and $(B)$ nine inch spherical remmeters.

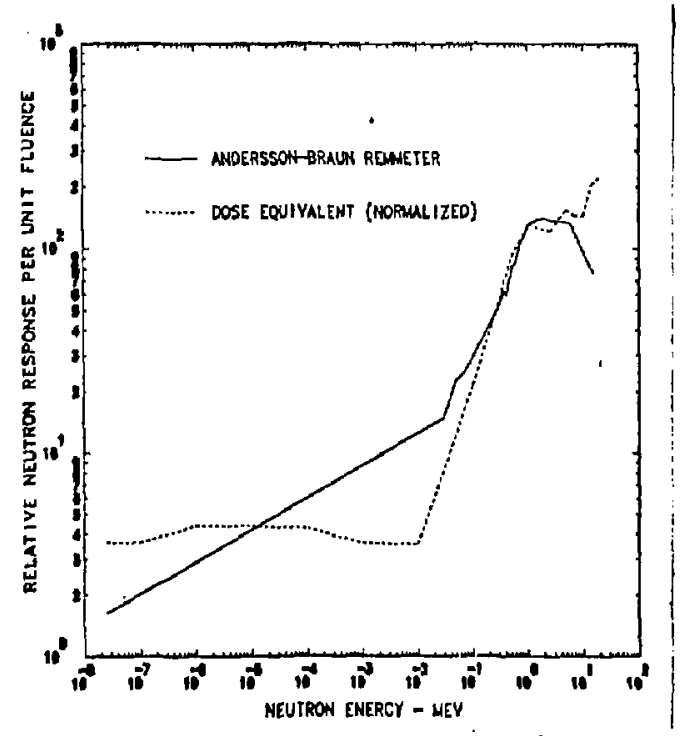

Figure 18. Measured Neutron energy response of an Andersson-Braun remmeter. 


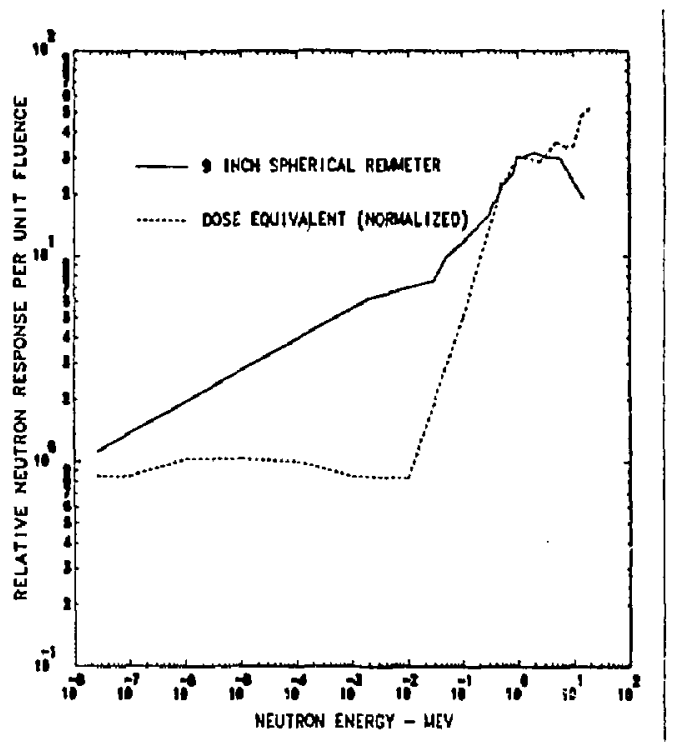

Figure 19. Measured neutron energy response of a nine inch spherical remmeter.

\section{Bonner Spheres}

The energy response of a moderated thermal neutron detector changes with moderator thickness. This point was made in introducing noderated remmeters. If we now emphasize the response variation with sphere size, we develop the concept of multisphere spectrometry. If neutron field measurements are made with a detector in the center of different spheres, we obtain a set of responses that can be used to infer the quality or rough energy spectrum of the neutron field. There are two basic requirements for this kind of measurement.

- A set of responses from detectors that have well-known and sufficiently different response functions.

and

- A mechanism (usually a computer code) for unfolding the response matrix.

If these requirements are inet, it is possible, with relatively modest resources, to make spectral measurements in an operational area, that are of sufficient quality for radiation protection purposes. Although not generally considered in the class of health physics survey measurements, spectral information can be used to determine the relative over- or under-response of dosimeters and renmeters (assuming energy response functions are known), and are useful in predicting shielding design changes necessary to reduce possible over exposures. 
The detectors most commonly used in multi or Bonner Sphere (Bra60) systems are $L$ iI scintillators or ${ }^{6} L$ if $T L D$ arrays. Calculations have been made of the energy response of these systems (Fig. 20, San73), as well as for activation detectors. The relative response curve shape is much more dependent on sphere size than detector type (as long as a detector with high thermal cross section is used). The detector type and size dictates the sensitivity for a given size sphere.

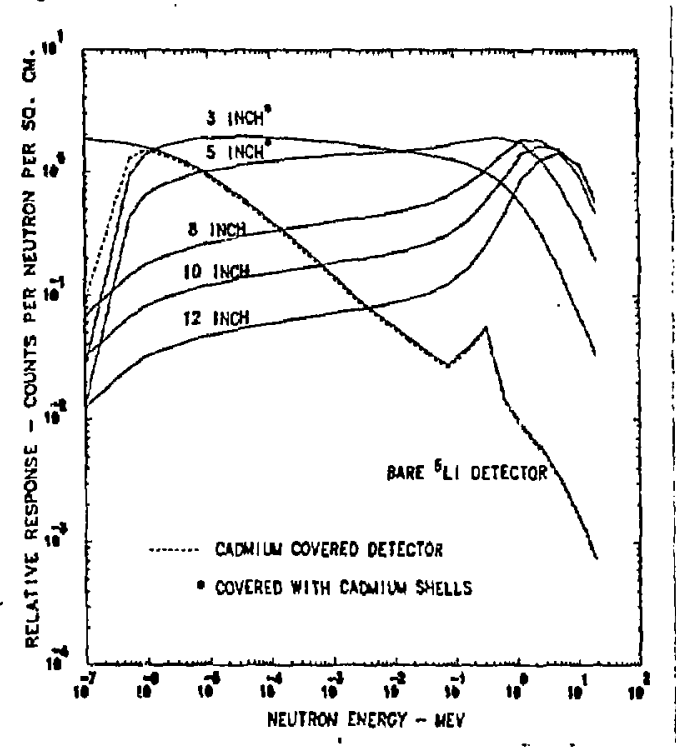

Figure 20. Response of Bonner spheres with a $0.5^{\prime \prime} \times 0.5^{\prime \prime}{ }^{\circ} \mathrm{LiI}$ detector.

The unfolding process can be done using one of a number of available codes (San76, Rou78, Hce67). Presently one must have access to at least a modest size computer, but it is likely that adequate codes will soon be developed to unfold multisphere data on minis or even desk top computers. If adequate response functions can be determined for $\mathrm{BF}_{3}$ moderated detectors, such as that already used in the 9 inch spherical remmeter, a health physicist vould be in a position to make low level neutron spectrum measurements with relative edse.

\section{CALIBRATION STRATEGIES}

\section{A. General Considerations}

When discussing dosimater calibrations, it is iniportant from the outset to remember that the energy response of a dosimeter can not be altered by calibration. The calibration process is a method of assigning the proper value of dosimeter response per unit dose equivalent, for a fixed application. If the dosimeter or survey instrument has an energy response that varies significantly in relation to the dose equivalent response, adequate consideration must be given to the energy characteristics of the operational field. It is quite commion, for example, to calibrate dosimeters with unmoderated ${ }^{252} \mathrm{Cf}$ fission neutrons or $B e(\alpha, n)$ source neutrons. If the dosimeters are to be used in highly moderated fieids such as those found at power reactors (SanBO, End80), serious spectrum dependent errors can result. The problem is illustrated in Fig. 21, A threshold detector (NTA, 
polycarbonate etc.) with responses above I Mev, will appear to have adequate sensitivities when calibrated with a rem of ${ }^{2}{ }^{2} \mathrm{Cf}$ neutrons. However, when used in the low energy environinent of a power reactor, they may be virtually insensitive, potentially underestimating doses by large factors. For example, under the conditions shown in Figure 21 , a polycarbonate detector would detect only about 19\% of the dose equivalent with $81 \%$ undetected. Table 2 presents predicted error ranges for typical dosimeters, based on spectral measurements by two separate groups (San80, Gri78). The spectral measurements were made at two different groups of reactors. The detector responses used, in some cases, cane from different references. However, the important point is to note the expected range of responses, and the large errors that could be encountered, if the spectral conditions are unkrown and inproper calibration sources are used. The detector response error spreads for a single facility will not be nearly as great as those shown in Table 2. However, the calibration normalization error would exist with use of the indicated sources.

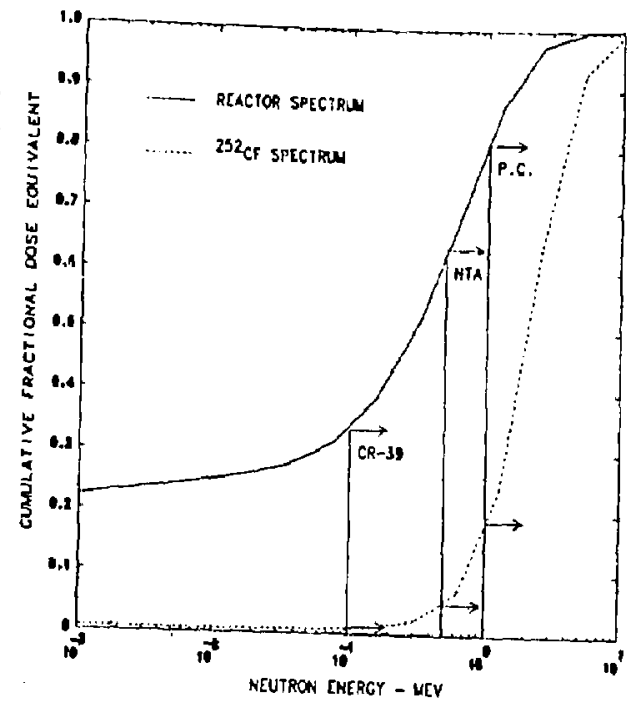

Figure 21. Comparison of cumulative fractional dose equivalents for moderated power reactor and 252 Cf calibration spectra, with detection thresholds for selected threshold detectors - CR39 (electrochemically etched), NTA and polycarbonate (P.C. - electrochemically
etched). 
Table 2. Calculated Dosimeter or Instrument Dose Equivalent Response in Rem, Assuming Calibration with I Rem of Unmoderated Hentrons

Calibration Source

Study I (San80)

${ }^{252} \mathrm{Cf} \quad$ PuBe
Stuciy 2 (Gri78)

$252 \mathrm{Cf}$

PuBe
Albedo (Hankins type)
$2.9-14$.
$5.8-27$.
10. -31 .
i4. -44.
NTA
$0.015-0.7 \quad 0.01-0.5$
$0.2-0.7$
$0.17-0.6$

Polycarbonate

(Electrochemically etched)

$$
\begin{array}{ll}
0.0-0.7 & 0.0-0.4 \\
1.3-3.3 & 1.4-3.5 \\
1.0-2.0 & 1.2-2.4
\end{array}
$$

9 inch remmeter

$1.4-2.0$

$1.6-2.2$

Andersson-Braun remmeter

$0.9-1.2$

i.0 -1.3

\section{B. In-field Calibration and Survey Techniques}

There are four ways of reduing the dosimetry errors

- Use relatively simple techniques to survey working areas and determine the spectral quality of the neutron fields.

- Avoid use of detectors that will be expected to have poor sensitivity based on energy response considerations.

- Use calibration fields whose spectra are more appropriate to the health physics application.

- Consider the use of in-field calibration techniques.

The first and last points are related, and described in more detaif e 3 sewhere (Gri80b). Measurements using a survey instrument probe, with two moderators of significantly different sizes, provide a measure of the relative contribution of intermediate and fast neutrons. One can make pairs of measurements very rapidly at a number of facility locations, and the distribution of response ratios (large to small moderator) provides a quick and effective indication of the overall spectral quality (fast to intermediate proportion), and the relative change in spectral quality. Measurements with a bare detector provide an additional estimate of the thermal contribution. The information obtained in this way, when compared with similar measurements of calibration sources, estimate how well the source natches the rork environment.

A specific example of the technique just described has been used successfully as an in-field calibration method for use with albedo dosimeters (Han75b). The relative response of a 3 inch moderator detector, covered with cadmiuni and a "Hankins" type cadmium wrapped albedo dosimeter, are quite similar (Fig. 22), so that the moderated detector $c$ an be considered a real time monitor with an albedo-like response. We have already shown that the same $\mathrm{BF}_{3}$ detector in a 9 inch sphere has a dose equivalent response. Therefore, the response ratio of the 9 inch to 3 inch moderated detector is proportional to the albedo calibration factor in dose equivalent per unit 
neutron induced T.L. response (Fig. 23, Han75b). The "g to 3 inch" survey is, therefore, a valid technique for establishing the proper albedo calibration factor and range of responses or probable error in a facility like a reactor.

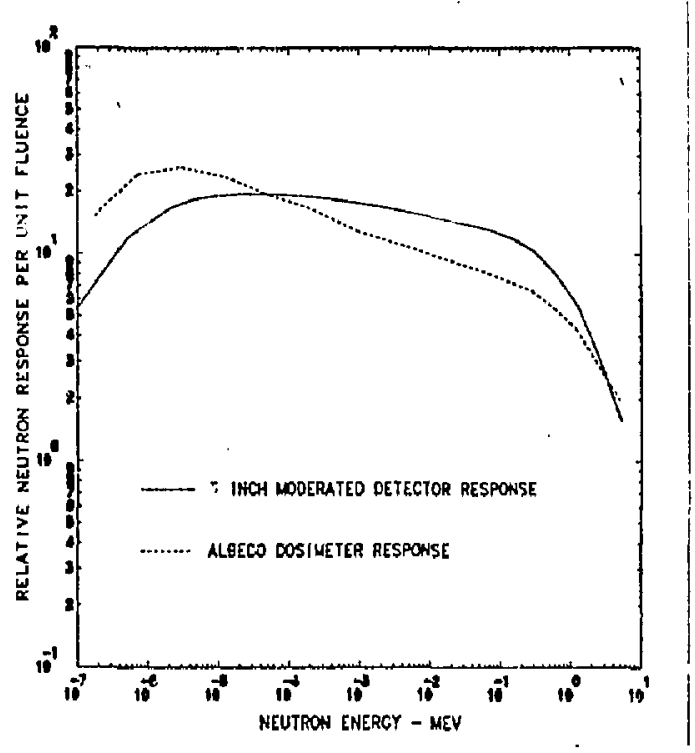

Figure 22. Comparison of the responses of an albedo and $3^{\prime \prime}$ moderator detector.

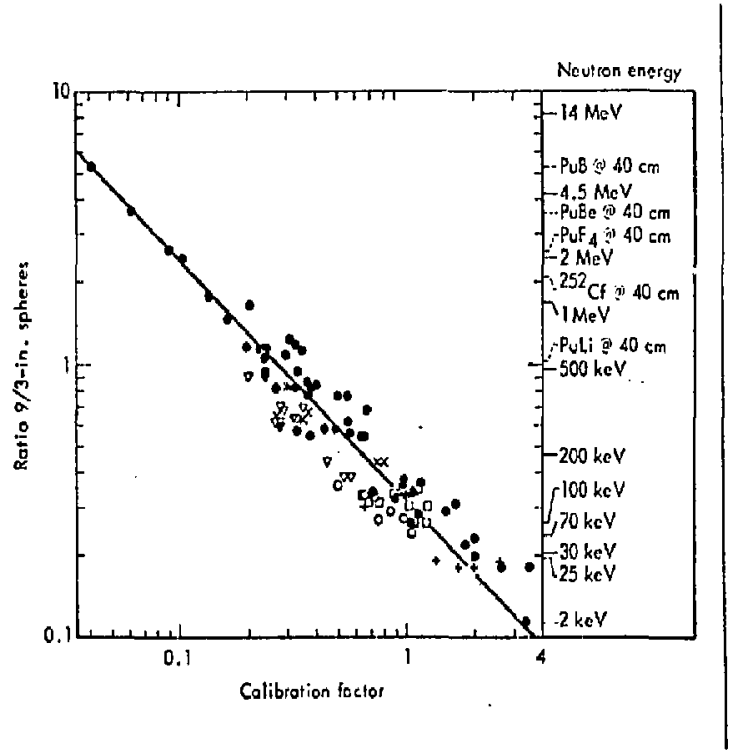

Figure 23. Albedo dosimeter calibration factor as a function of the nine-tothree and moderated detector response ratio. 


\section{Calibration Souce Spectra}

All things in moderation is quite appropriate for calibration source spectra used in reactor applications. He have discussed the problems associated with calibration using unmoderated, laboratory sources. However, in many situations, there is little alternative available. Moderators that effectively sinulate low energy reactor spectra are obviously heavy and expensive. Some laboratories have used an array of moderators for calibration work (Gri78), but the effort and expense involved is probably beyond the resource of most dosimetry programs. A dosimetrist may be able to work toward establishing one moderated source configuration. If so, a study by the National Bureau of Standards has identified use of a ${ }^{252} \mathrm{Cf}$ source in a $15 \mathrm{~cm}$ radius sphere of $\mathrm{O}_{2} \mathrm{O}$ as being a reasonable approximation to reactor spectra ( $\$$ ch80), at least as $f$ ar as the dosimeter response is concerned. It would certainly be better than an unmoderated source, and would help identify gross dosimeter sensitivity problems. Even this configuration is probably outside the resources of most facilities, however versions of the prescribed configuration will probably be available at the NBS and as part of the NRC dosimetry testing program. Measurement techniques using the neutrons in the operational area are probably the best way of calibrating dosimeters, while source calibrations provide a day to day measure of overall system precision.

\section{FUTURE DEVELOPMENTS?}

Every well-rounded health physicist should be familiar with new developments, even though they can not be applied immediately. A little space is devoted to some items that may likely be of interest in the near future.

\section{A. Regulatory}

Little definitive information is available about pending changes in neutron standards. The NRC has taken seriously recent warnings and reconmendations to make neutron exposure standards more stringent (Ros77, Ros78). However, a recent re-evaluation of the radiation dose data from Hiroshima and Nagasaki (Loe8l) have put the validity of these recomendations in question. The drive toward change may have been arrested until the new study can be fully evaluated.

\section{B. Dosimeters}

Development of micro-electronics techniques over recent years provide a potentially fruitful basis for new dosinetry developments. It is very likely that we will see development of new, sensitive, real time pocket dosimeters, enploying solid state detectors in the next five years. The development of organic solid state detectors is not out of the question.

One interesting application of micro-electronics leads to the third of the electrical breakdown detection techniques. The thin film detector (Tom77, Kle77) uses metal-an-silicon (MOS) detector to register charged particles (such as fission fragments). In operation, the MOS capacitor is maintained just below the breakdown potential, when the charged particie enters the capacitor, causing a breakdown that can be detected by a pulse counter. Such a system, now under study at LLNL, could be miniaturized and worn as a real-time pocket dosimeter. 
Other detection techniques are now under study, but problenis of sensitivity or high photon response have prevented widespread application.

- TLO with hydrogenous radiators - The advantage of associating any one of a number of TLD materials with an hydrogenous radiator is enticing, and has been studied in various forms for many years. External radiators do not provide sufficient response. Attempts to mix materials with the TLD, such as parasexiphenyl (Bec73, Per74), glucose (B1u72); or use of hydrogen doped inorganic phosphors (Mor77), have been hampered by high cost, sensitivity to protons and some production problems.

- LET-dependent, differential glow-peaks in TLD - The studies on this technique (End75, Luc77a, Kap77) have been encouraging, and continue. Sensitivity and photon response have prevented funl implementation.

- Lyoluminescence - The study of light enission from irradiated materials (mannose, for example) when they are dissolved is of interest because the materials have an organic, tissue related composition. In particular, of course, the hydrogen content is high. Unfortunately, so is the photon sensitivity, and the lower limit of neutron detection (Ett77a, Ett77b).

- Neutron damage effects an electrical conductivity - A relatively old dosimeter concept (Bec73b), efforts continue to improve the sensitivity of silicon diodes (Luc77b). Conductivity in plastics has and is being studied (fad77), but has not received wide interest, partly because of photon sensitivity.

- Superheated drop detector - This is a relatively new technique, and is an intriguing fluid track detector (Apf79). A liquid such as Freon is injected into a viscous gel under pressure. When the pressure is released, the Freon becomes superheated. A charged particle. (such as a neutron recoil) can trigger nucleation, resulting in formation of a tiny gas bubble.

The volume of gas production can be related to the fluence or dose. Since a minimum ionization density is required to form unstable bubbles (those that do not collapse), the detector can be made insensitive to photons. In fact, the parameters of production caln be adjusted to change the response in predictable ways. The technique is fairly recent, and problems such as temperature sensitivity need to be studied, but it does show promise.

- Track detectors - The eriergetic work on CR-39, just when otiver track detectors had been fairly thoroughly studied, indicates that there is a)ways potential for new, sensitive materials.

\section{Survey Instruments}

As ide from potential redesign and modification of existing remmeters, not much is new. However, a prototype instrument based on an L.E.T. chamber is under study at EG\&G. The unit is much lighter than moderator remmeters, and 
very preliminary, unpublished tests indicate that the energy response is as good as existing units. The sensitivity, however, is not as good as the Andersson-Braun or 9 inch renmeters. That may be changed with improved design.

\section{SUMMARY}

There tends to be a lot of pessimism these days about neutron dosimetry. Much of this comes from people having had bad experiences with some of the old systems and techniques. Certainly, there is not a single dosimeter that is satisfactory for all applications. But, recent studies and developments have shown that some dosimetry, such as albedo detectors, can be used effectively if the neutron field quality does not vary seriously throughout a facility. Some additional points are clear.

- Some dosimeters are inappropriate for some applications. There must be sufficient analysis and courage to avoid use of such dosimeters, even if they are traditiona?.

- Simple techniques are available, even to a health physicist of modest means, to characterize the working area and understand the important parameters.

- In some applications, a combination of dosimeter detecting elements may be of specific advantage and should be considered to combat poor energy response and photon sensitivity problems.

- An unmoderated calibration source, in most cases, is a very poor tool for establishing the calibration factor to be applied to use of a dosimeter. These sources should be viewed primarily as system check sources that will help maintain overall systems precision and reproducibility, but not accuracy.

- Some interesting techniques and detectors are under study, and should contribute to continued solution of neutron problems in the next few years.

- In general, more effort may be needed to provide an effective neutron dosimetry program than that expended for photon dosimetry.

For those interested in more detailed analys is of the problems in this field, there are other references (Bra80, Gri79). 


\section{REFERENCES}

ANSI69 American National Standards Institute, 1969, American National Standard Dosimetry for Criticality Accidents, AMST NT3.3-1969.

ANSI76 American National Standards Institute, 1976, Anerican Nationa] Standard for Personnel Neutron Dosimeters (Neutron Energies Less than $20 \mathrm{MeV}$ ), ANSI N319-1976.

ANSI81 American National Standards Institute, 1981, American National Standard, Criteria for Testing Personnel Dosimetry Performance, ANSI NIS.TI (Uraft).

Als74 Alsmiller R.G., Jr., and Barish J., 1974, "The Calculated Response of ${ }^{6} L$ if Albedo Dosimeters to Neutrons with Energies $<400 \mathrm{MeV}, "$ Health Physics, 26, No. I

Ain79 Al-Najjar, Bull R.K. and Durrani S.A., 1979, "Electrochemical Etching of CR-39 Plastic; Applications to Radiation Dosimetry," Nuclear Tracks, 3, 169-183.

And63 Andersson I.0. and Braun J., 1963, "A Neutron Rem Counter with Uniform Sensitivity from 0.025 el to $10 \mathrm{MeV}$," in: Neutron Dosimetry, Vol. II, p. 87 (Vienna: IAEA).

Apf79 Apfel R.E., 1979, "The Superheated Drop Detector," Nuc. Inst. Meth. 1623, Hos. 1-3, pp 603-608.

Aux68 Auxier J.A., Snyder H.S., Jones T.D., 1968, in Radiation Dosimetry Vol. 1, 2nd Edn (ATTIX, F.H., ROESCH, W.C., Eds), Academis Press, New York, Chapter 6.

Bec73a Becker K., Tham T.D. and Haywood F.F., 1973, "Compounds of TLOS in High-Melting Organics for Fast Neutron Personnel Dosimetry," in: Proc. 3rd Int. Cong. IRPA, Vol. 1, p. 584.

Bec73b Becker K., 1973, "Solid State Dosimetry, Chp. VI (Cleveland Ohio: CRC Press).

Bec75 Becker K. and Abd-E]-Razek J., 1975, "Automatic Spark Counting of Fast-Neutron-Induced Recoil-Particle Tracks in Polyner Foils," Huc 1. Instrum. Meth. 124, 557.

Blu72 Blum, E., Berley D.K. and Heather J.D., 7972, "The Use of CaSC4:Im Powder for Fast Neutron Dosimetry," Pnysics Med. Biol. $17,667$.

Bra60 Bramblett R.L., Ewing R.E. and Bonner T.W., 1960, "A New Type of Neutron Spectrometer," Nucl. Inst. Meth. 9, p.?.

Bra30 Brackentush L.W., Endres G.H.R., Selby J.M. and Vallario E.J., 1980, Personnel Neutron Dosimetry at Department of Energy Facilities, Pacif ic Borthwest Laboratory Report PNL-32]3. 


\section{REFERENCES (Cont inued)}

Cas78

Cassou R.M. and Benton E.V., 1978, "Properties and Applications of CR-39 Polymeric Nuclear Track Detector," Nuclear Track Detection 2, 173-179.

Car79 Cartwright B.G., Shirk E.K. and Price P.B., 1979, "A Nuclear-Track-Recording Polymer of Unique Sensitivity and Resolution," Nucl. Inst. Meth. 153, pp. 457-460.

Cro70 Cross W.G. and Tommasino L., 1970, "A Rapid Reading Technique for Nuclear Particle Uamage Tracks in Thin Foils," Radiat. Effects 6 , 85.

Cro75 Cross W.G. and Ing H., 1975, "The Use of ${ }^{237} \mathrm{~Np}$ in Personnel Dosimeters for Fast Neutrons," Health Phys. 28, 511.

Dis73 Distenfeld C.H., 1973, "Sumrnary. of Personnel Neutron Dosimetry Development at Brookhaven National Laboratory, " in: Fourth AEC Workshop on Personnel Neutron Dosimetry, Report No. BNWL-1777, p. 20, Battelle-Pacific Northwest Laboratories, Richland, WA.

Dut79 Dutrannois J., Hofert M., Sullivan A.H. and Tryn J.H.N., 1979, "A Personnel Neutron Monitoring System Based on Solid State Nuclear Track Detectors," Proc. 10th Int. Conf. on Solid State Nuclear Track Detectors, Lyon, France pp. 527-532.

Eis80 Eisen Y., Sharnai Y, Ovadia E., Karpinovich Z., Faernan S. and Schlesinger T., 1980, "Development of Neutron Dosimeters for Fast and Epithermal Neutrons," 5 th International Congress of the International Radiation Protection Association, Vol. II, 157-160.

Eis81 Eisenhauer C. and Schwartz R., 1981, "Difficulties in Calculating Spectrum-Averaged Values of Neutron Dose Equivalent," Health Phys. (In Press).

End75 Endres G.W.R., 1975, "Fast Neutron Dosimetry Using High Temperature Peaks in Lif and $\mathrm{CaF}_{2}: T m, "$ in: 5th ERDA Workshop on Personnel Neutron Dosimetry, Report No. BNlLL-1934, p. 32, Battelle-Pacific Northwest Laboratories, Richland, WA.

End80 Endres G.H.R., Faust L.G., Brackenbush L.H., and Griffith R.V., 1980, "Neutron Spectra and Dose Equivalent Inside Reactor Containment," Proc. 5th IRPA Congress, Jerusalem, Israel, pp. 89-92.

Ett77a. Ettinger K.V., Takavar A., Mallard J.R. and Buchau G., 1977, "Lyoluminescence Dosimetry with Sensitizers," Proc. 4th Int. Congr. IRPA, Paris, France, p. 1269 (IRPA).

Ett77b Ettinger K.V., Mallard J.R., Spirath S. and Takavar A., 1977, "Lyoluminescence Dosimetry with Some Saccharides," Physics Med. Biol. 22, 481 . 


\section{REFERENCES (Cont inued)}

Fal7l Falk R.8., 1977, "A Personnel Neutron Dosimeter Using Lithium Fluoride Thermoluminescent Dosimeters," Report No. RFP-1581, Dow Cheinical Company, Golden, co.

Fad77 Fadel M.A., 1977, "A Devised Electric Conductivity Method for Measuring Personnel Neutron Doses," Radiat. Effects 31, 220.

Fle67 Fleischer R.L., Price P.B., Walker R.M. and Hubbard E.L., 1967, "Criterion for Registration in Dielectric Track Detectors," Phys. Rev. 156, 353-355.

Fle75 Fleishcer R.L., Price P.B. and Walker R.M., 1975, Nuclear Tracks in Solids, University of California Press, Berkeley and LoS Angeles, California.

Gri78 Griffith R.V., Slaughter D.R., Patterson H.W., Beach J.L., Frank E.6., Rueppel D.W. and Fisher J.C., 1978, "Multi-Technique Characterization of Neutron Fields from Moderated $252 \mathrm{Cf}$ and 23"PuBe Sources," Proc. IAEA Symposium, National and International Standardization of Radiation Dosimetry, Vol. II, 167-188.

Gri79 Griffith R.V., Hankins D.E., Gamage R.B., Tomasino L. and Wheeler R.V., 1979, "Recent Developments in Personnel Neutron Dosimetry - A Review," Health Phys. Vol. 36, 235-260.

Gri80a Griffith R.V., Fisher J.C., Tomiasino L. and Zapparolli G., 1980, "Developinent of a Personnel Neutron Dosineter/Spectrometer," Proc. 5th International Congress of the International Radiation Protection Association, Vol. II, 169-172.

Gris0b Griffith R.V. and Hankins D.E., "A Systematic Approach to Personnel Meutron Monitoring," Proc. 5th International Congress, International Radiation Protection Association, Vol. I, 237-244.

Gri81 Griffith R.V., Thorngate J.H., Davidson K.H., Rueppel D.H., Fisher J.C., Tommasino L. and Zapparolli G., 1981, "Honoenergetic Neutron Respone of Selected Etch Plastics for Personnel Neutron Dosimetry," Radiation Protection Dosimetry, Vol 1, No. 1, 6?-71.

Hanib7 Hankins D.E., 1976, A Modified-Sphere Neutron Detector, Los Alamos Scientific Laboratory Report $L A-3595$.

Har72 Harvey J.R., Hudd W.H.R. and Townsend S., 1972, "Personnel Dosimeter for Measuring the Dose from Thermal and Intermediate-Energy Neutrons and from Gamna and Beta Radiation," in: IAEA Symposium on Neutron Monitoring for Radiation Protection Purposes (V ienna: IAEA).

Han73 Hankins O.E., 1973, "A Small Inexpensive Albedo-Neutron Dosimeter," Report No. LA-526I, Los Alamos Scientific Laboratory, Los Alamos, NM. 
$\operatorname{Han} 74$

Hankins D.W. and Cortez J.R., 1974, Directional Response and Energy Dependence of Four Neutron Remmeters, LOS ATarnos Scientific Laboratory Report LA-5528.

Han75a Hankins 0.E., 1975, "Energy Dependence of Four Neutron Remmeter Instrunients," Health Phys. 28, 305.

Han750 Hankins D.E., 1975, "The Effect of Energy Dependence on the Evaluations of Albedo Neutron Dosimeters," in: Proc. 9th Midyear Topical Symposium, Health Physics Society, Denver, p. 861.

Han77 Hankins 0.E., 1977, "Energy Dependence Measurements of Remmeters and Albedo Neutron Dosimeters at Neutron Energies of Therinal and between $2 \mathrm{keV}$ and $5.67 \mathrm{MeV}$, in: Proc. Int. Radiation Protection Association IVth Int. Cong., Paris, p. 553.

Han78 Hankins D.E. and Griffith R.V., 1978, "A Survey of Neutrons Inside the Containnent of a Pressurized Water Reactor," Proc. ANS Winter Neeting, Washington, D.C., Lawrence Livermore Laboratory Preprint UCRL-81346.

Har78 Harrison K.G., 1978, "A Neutron Dosimeter Based on ${ }^{237}$ Np Fission," Nucl. Inst. Meth. 157, 169-178.

Han72a Hankins D.E., 1972, "Factors Affecting the Design of Albedo Neutron Dosimeters Containing Lithium Fluoride Thermoluminescent Dosimeters," Report No. LA-4832, Los Alamos Scientific Laboratory, Los ATamos, NM.

Han72b Hankins D.E., 1973, "Design of Albedo Neutron Dosimeters," in: lleutron Monitoring for Radiation Protection Purposes, p. 15. (Vienna: IAEA).

Hoy72 Hoy J.E., 1972, "An Albedo-Type Personnel Neutron Dosimeter," Heaith Phys. 23, 285.

Hur58 Hurst G.S. and Ritchie R.H., 1958, Radiation Accidents: Dosimetric Aspects of Neutron and Gamma Ray Exposures, Oak Kidge National Laboratory Report ORNL-2748 Pt. A.

IAEA70 International Atomic Energy Agency, 1970, Nuclear Accident Dosimetry Systems, Proc. of a panel.

IAEA71 Iniernational Atomic Energy Agency, (1971) Biophysical Aspects of Radiation Quality, Proceedings of a Symposium, Lucas Heights, Austratia.

IAEA78 International Atomic Energy Agency, 1978, Conpendium of Neutron Spectra in Criticality Accijent Dosimetry, IAEA Technical Report Series No. 180.

ICRP/ICRUE3 International Commission on Radiological Protection and International Commission on Radiation Units and Measurements, 1963, "Report on the RBE Committee," Health Phys. 9, 357. 
ICRU69 International Commission on Radiation Units and Measurements, 1969, Neutron Fluence, Neutron Spectra and Kerma, ICRU Report 13.

ICRU75 International Commission on Radiation Units and Measurements, $19 \%$, Conceptual Basis for the Determination of Dose Equivalent, ICRII Report. 25.

Jas75 Jasiak J, and Piesch E., 1975, "Automatically Spark Counting of Neutron Induced Recoil Tracks in Polycarbonate Foils," Nucl. Instrum. Meth. 128, 447.

Kapi7 Kapsar B.M. and Lucas A.C., 1977, "Neutron and Gamma Ray Detection Using Thermoluminescence of $\mathrm{CaF}_{2}: \mathrm{Tm}, "$ in: Abstracts of the 22nd Annua? Meeting of the Health Physics Society, At ] anta, GA, paper $P / 14$.

Kle77 Kiein N., Solomon P., and Tommasino, L., 1976, "Fission Fragment Detection by Thin Film Capacitors - II, Current Pulse Counter and Mechanisms," Nuclear Track Detection, Vol. 1, No. 1, 71-74.

Klu81 Kluge $H$. and Aiberts $H_{.}$, 1981, "Neutron Fluence-to-Dose Equivalent Conversion Factors," Heal th Phys. (In Press).

Loe81 Loewe H.L. and Mendelsohn E., 1981, Revised Dose Estimates at Hiroshima and Nagasaki, Lawrence Livermore National Laboratory Report UCRL-85446 (Preprint) Submitted to Health Physics.

Luc77a Lucas A.C. and Kapsar B.M., 1977, "The Thermoluminescence of Thu! ium Doped Calcium Fluoride," in: Proc. 5th Int. Conf. on Luminescence Dosinetry, Sao Paulo, Brazi? (Edited by Scharmann A.), p. 131. (I. Physikalisches institute, Justus-LiebigUniversitat, Giessen, West Germany).

Luc77b Lucas A.C., 1977, "The Design of a Silicon PIN Diode for Fast Neutron Dosimetry," in: Abstracts of the 22nd Annual Meeting of the Iiealth Physics Society, Atlanta, GA, paper $P / 13$.

Maj80 Majborn B., 1980, A Critical Review of Nuclear Accident Dosimeters, Commission of the European Communities, Radioprotection, Report EUR 6838.

Mce67 McElroy W.M., Berg S., Crockett T. and Hawkins R.G., 1967, A Computer-Automated Iterative Method for Neutron Flux Determination by Foil Activation, Air Force Weapons Laboratory Report AFWL-TR-67-4T, Vol. I-IV.

Mor77 Morato S.P. and Nambi K.S.V., 1977, "Development of Hydrogen-Doped TL Phosphors for Fast Heutron Dosimetry," in: Proc. 5th Int. Conf. on Luminescence Dosimetry, Sao Paulo, Brazil (Edited by Scharmann A.), p. 155. (I. Physikalisches Institute, Justus-Liebig-Universitat, Giessen, hest Germany).

NCRP54 National Council on Radiation Protection and Measurements, 1954, Permissible Dose from External Sources of Ionizing Radiation, MCRP Report T/, Wational Bureau of Standards handbook 59 . 


\section{REFERENCES (Continued)}

NCRP7) National Council on Radiation Protection and Measurements, 1971, Protection Against Neutron Radiation, NCRP Report. 38.

0sh73 Oshino M., 1973, "Response of NTA Personnel Neutron Monitoring Film Horn on Human Phantom," Health Phys. 24, 71.

Per74 Perdue P.T. and Baldwin W.H., 1974, "Development of a Stable, High Meiting Point Organic Scintillator for Applications in Radioprotection," in: Abstracts of Papers, 19th Annual Meeting of the Health Physics Society, Houston, TX, paper $P / 62$.

Pie74 Piesch E. and Burgkhardt B., 1974, "An Lif Albedo Neutron Dosimeter for Personnel Monitoring in Mixed Radiation Fields," in: 4th Int. Conf. on Luminescence Dosimetry (Institute of Nuclear Physics, Krakow, Poland).

Pie77 Piesch E., 1977, "Progress in Albedo Neutron Dosimetry," Nuc. Inst. and Meth. 145, 613-619.

Pri62 Price P.B. and Walker R.M., 1962, "Chemical Etching of Charge-Particle Tracks in Solids," J. App 1. Phys., 33, 3407.

Pre73 Pretre S., 1973, "Personnel Neutron Dosineter, Based on Automatic Fission-Track and Spark Counting for Routine and Enjergency Use," in: Proc. Symp. Neutron Monitoring for Radiation Protection Purposes, vol. II, p. 99 (Vienna: IAEA).

Rei58 Reinhardt P.W. and Davis F.J., 1958, "Improvenents in the Threshold Detector Method of Fast Neutron Dosimetry," Health Phys. I, 169.

Ros77 Rossi H.H., 1977, "A Proposal for Revision of the Quality Factor," Rad. and Environmental Biophysics $14(4), 275$.

Ros78 Rossi H.H. and Mays C.W., 1978, "Leukemia Risk from Neutrons," Heaitn Phys. $34(4), 353$.

Rou78 Routti J.T. and Sandberg J.V., 1978, General Purpose Unfolding Program LOUHI 78 with Linear and Nonlinear ReguTarizations, Helsinki University of Technology Report TRK-F-A359.

Rog79 Rogers D.H.0., 1979, "Why Not to Trust a Neutron Remmeter," Health Phys. 37, No. 6, 735-742.

Rog78 Rogers D.H.0., 1978, "Conversion of Neutron/cil ${ }^{2}$ to Rem," Health Phys, 34, No. 4, 395-396.

San73 Sanna R.S., 1973, "Thirty-One Group Response Matrices for the Hultisphere Neutron Spectrometer Over the Range Thermal to 400 MeV," USAEC Heaith and Safety Laboratory Report HASL-257. 
Say74 Sayed A.M. and Piesch E., 1974, "Study of the Latent Fading of the NTA Film and Track Etching Detectors at Various Temperatures and Humidities," Report No. KFK-2032, Kernforschungszentrum, Kar]sruhe, West Germany.

San76 Sanna R.S., 1976, Modification of an Interative Code for Unfolding Neutron Spectra from Multisphere Data, USERDA Report RASL-3IT.

San80 Sanna R.S., Hajnal F., McLaughlin J.E., and Ryan M., 1980, Spectrometric Heasurements With in the Containments of 8 PWRS - A Data Compilation; 00 E Environmental Measurements Laboratory Report - EML -376 .

Sch80 Schwartz R.B. and Eisenhaver C.M., 1980, The Design and Construction of a 0,0 -Moderated ${ }^{252} \mathrm{Cf}$ Source for Calibrating Neutron Personnel Dostmeters Used at Nuclear Power Reactors," National Bureau of Standards, Prepared for U.5. Nuctear Regulatory Commission, NUREG/CR-1204.

Soh72 Sohrabi M, and Becker K., 1972, "Fast Neutron Personnel Monitoring by Fission Fragment Registration from ${ }^{237} \mathrm{~Np}, "$ Nucl. Inst. Meth. 104, 409-411.

Soh74 Sohrabi M., 1974, "The Amplification of Recoil Particle Tracks in Polymers and Its Application in Fast Neutron Personnel Dosimetry," Health Phys. 27, 598.

Ton70 Tomnasino L., 1970, "Electrochemical Etching of Damaged Track Detectors by H.V. Pulse and Sinusoided Waveforms," Report No. RT/PROT (71) 1970, Comitato Nazionale Energia Nucleare, Rome. Also: Italian Patent No. $51929 \mathrm{~A} / 70$.

Tom77 Tommasino L., Kle in N. and Solomon P., 1977, "Fission fragment Detection by Thin Film Capacitors - I. Breakdown Counter," Nuclear Track Detection, Vol. 1, 201, 63-70.

Tym73 Tyrions B.J., Tuyn J.W.N. and Baarli J., 1973, "System for Personnel Dosimetry in Mixed Radiation Fields," in: Proc. Symp. Neutron Monitoring for Radiation Protection Purposes, vol. II, 'p.' 63 (Vienna: IAEA).

Wag80 Wagner S.R., 1980, "Is the Dose Equivalent Index a Quantity to be Measured?" Proc, 5th Cong. International Radiation Proteition Association, Vol. 1, 163-166.

Yul73 Yule T.V., 1973, "The Solid State Track-Recorder Fast-Neutron Dosimeter Enployed at Argonne National Laboratory," in: Fourth AEC Workshop on Personnel Neutron Oosimetry, Report No. Blidl-1777, p. 51, Battelle-Pacific Northwest Laboratories, Richland, WA. 


\title{
DISII. IIVII:R
}

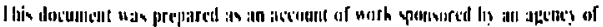

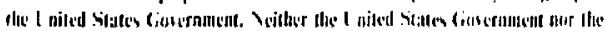

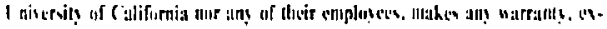

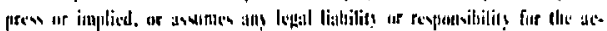

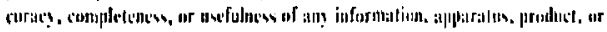

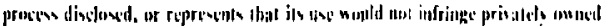

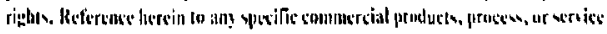

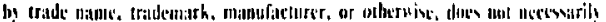

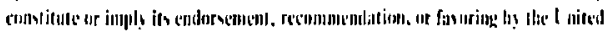

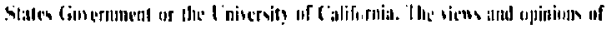

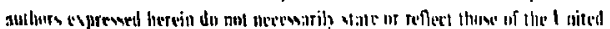

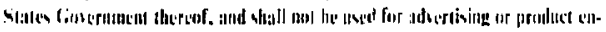

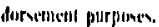

*This work was performed under the auspices of the U.S. Department of Energy by Lawrence Livermore Laboratory under contract No. W-7405-Eng-48. 